University of Wisconsin Milwaukee

UWM Digital Commons

Theses and Dissertations

May 2018

\title{
An Evaluation of Parent Preference for Prompting Procedures
}

\author{
Mary Halbur \\ University of Wisconsin-Milwaukee
}

Follow this and additional works at: https://dc.uwm.edu/etd

Part of the Applied Behavior Analysis Commons, and the Other Psychology Commons

\section{Recommended Citation}

Halbur, Mary, "An Evaluation of Parent Preference for Prompting Procedures" (2018). Theses and Dissertations. 1816.

https://dc.uwm.edu/etd/1816

This Thesis is brought to you for free and open access by UWM Digital Commons. It has been accepted for inclusion in Theses and Dissertations by an authorized administrator of UWM Digital Commons. For more information, please contact open-access@uwm.edu. 


\title{
AN EVALUATION OF PARENT PREFERENCE FOR PROMPTING PROCEDURES
}

by

Mary E. Halbur

A Thesis Submitted in

Partial Fulfillment of the

Requirements for the Degree of

\author{
Master of Science \\ in Psychology
}

at

University of Wisconsin - Milwaukee

May 2018 


\begin{abstract}
AN EVALUATION OF PARENT PREFERENCE FOR PROMPTING PROCEDURES
\end{abstract}

by

Mary E. Halbur

University of Wisconsin - Milwaukee, 2018

Under the Supervision of Dr. Tiffany Kodak

Previous researchers have suggested that parent participation in intervention can enhance intervention and promote generalization of skills across settings. Thus, parents should be trained to implement behavioral interventions. The purpose of the current investigation was to evaluate parent preference for and acceptability of three commonly used prompting procedures.

Experimenters trained parents of children with disabilities to use three evidence-based prompting strategies (i.e., least-to-most, most-to-least, and a progressive prompt delay). Once the parent reached the mastery criteria with each prompting procedure, his/her preference for each of the strategies was evaluated using a concurrent-chains arrangement. Additionally, treatment acceptability of all procedures was measured multiple times throughout the study. All participants met the mastery criteria for each of the prompting procedures and showed a preference for least-to-most prompting. Results suggested that parents' acceptability for procedures prior to training were different than post-training/post-child practice. In addition, acceptability rating scores obtained at the end of the investigation corresponded to preference of intervention during the concurrent-chains arrangement. The data obtained during this study support the utility of objective measures for studying preference for behavioral skill-acquisition procedures. 


\section{TABLE OF CONTENTS}

Abstract ...........................................................................................................

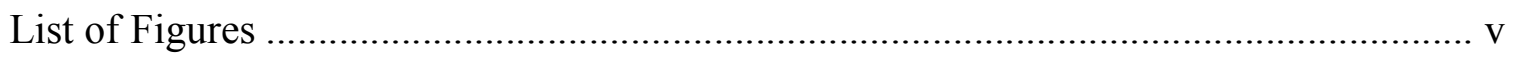

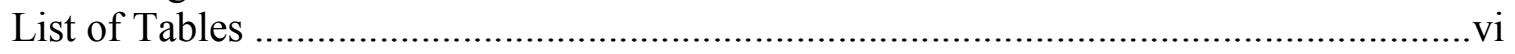

\section{CHAPTER}

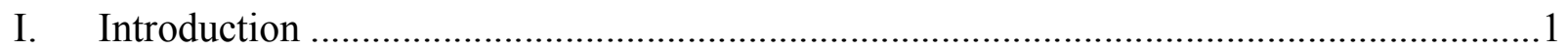

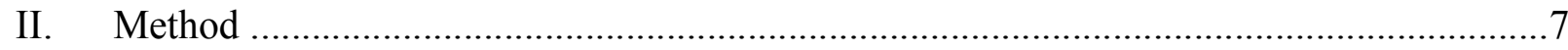

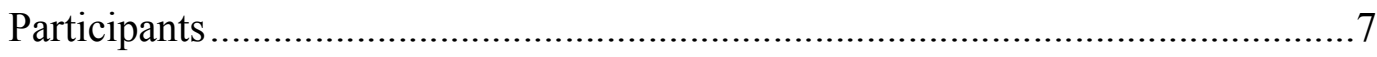

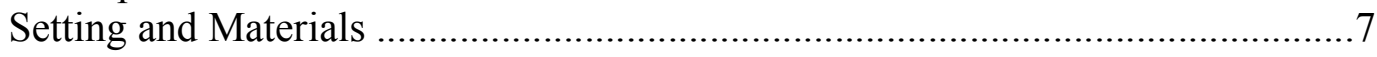

Response Measurement and Interobserver Agreement …..............................

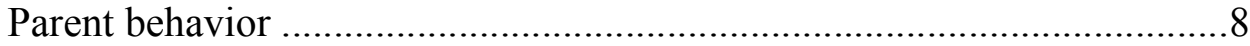

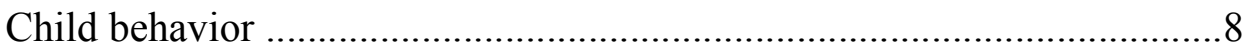

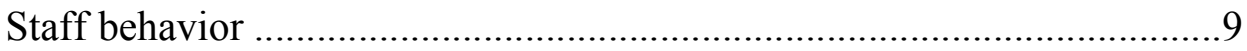

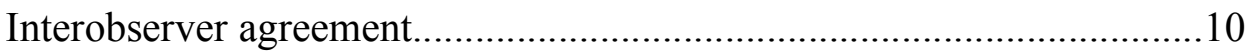

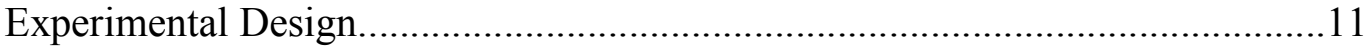

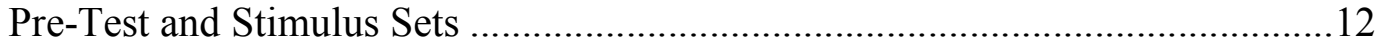

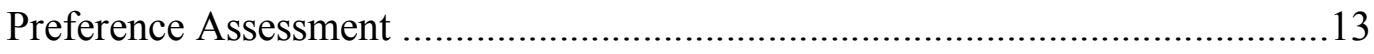

Prompting Procedures .................................................................................... 13

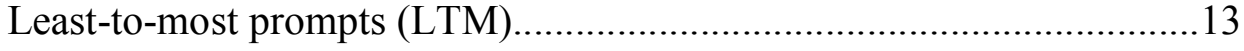

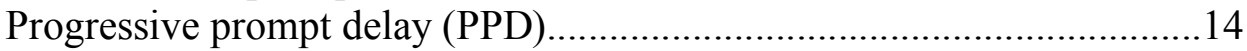

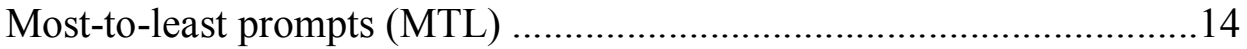

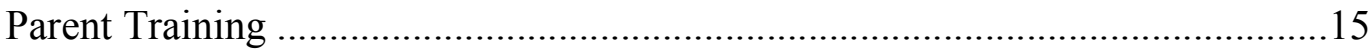

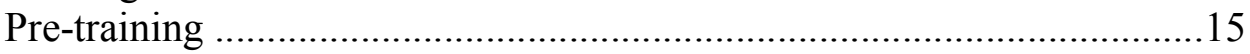

Behavioral skills training ...........................................................16

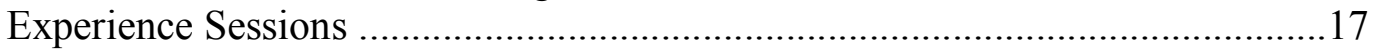

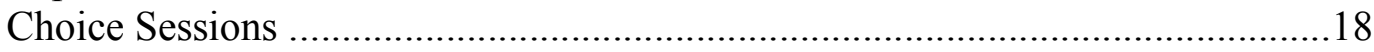

Treatment Acceptability ..................................................................... 18

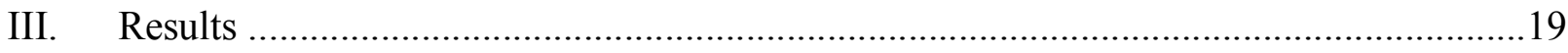

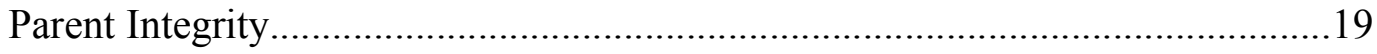

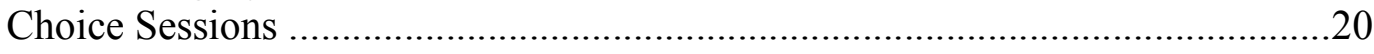

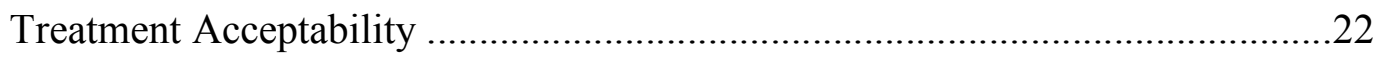

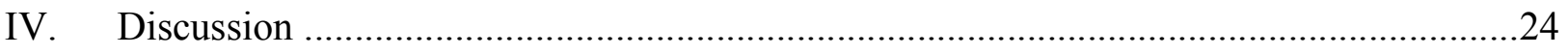

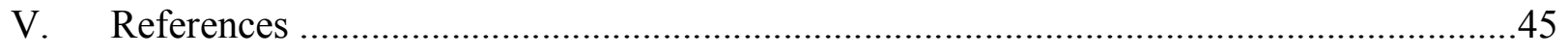

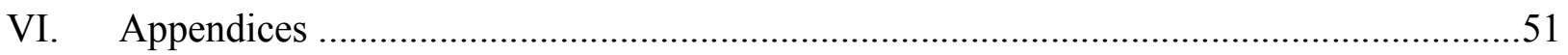

Appendix A. LTM flowchart................................................................51

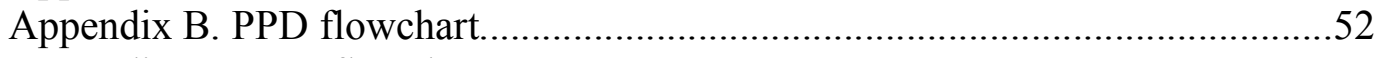

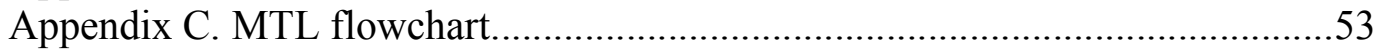


Appendix D. Sequence of study training procedures.....................................54

Appendix E. Example of parent instruction cards............................................55

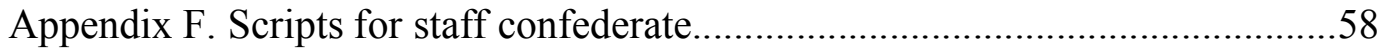

Appendix G. Feedback scripts......................................................................61

Appendix H. Treatment evaluation inventory short form revised.......................67

Appendix I. Treatment acceptability rating scale...............................................69 


\section{LIST OF FIGURES}

Figure 1. Treatment integrity for Mrs. Roberts ……………....................................................

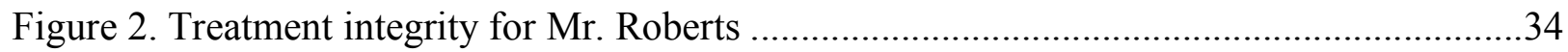

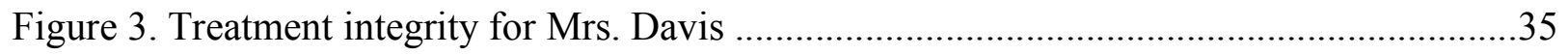

Figure 4. Treatment integrity for Mrs. Sullivan .....................................................................

Figure 5. Cumulative treatment selections for Mrs. Roberts ………………………….............37

Figure 6. Cumulative treatment selections for Mr. Roberts ....................................................38

Figure 7. Cumulative treatment selections for Mrs. Davis............................................................39

Figure 8. Cumulative treatment selections for Mrs. Sullivan ...................................................40

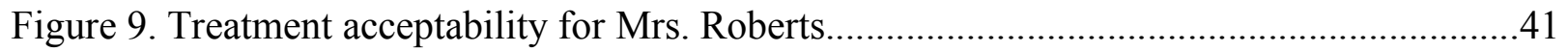

Figure 10. Treatment acceptability for Mr. Roberts.............................................................42

Figure 11. Treatment acceptability for Mrs. Davis...................................................................43

Figure 12. Treatment acceptability for Mrs. Sullivan..............................................................4 


\section{LIST OF TABLES}

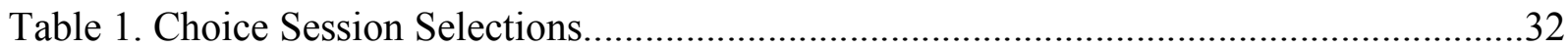




\section{ACKNOWLEDGMENTS}

I would like to thank my advisor, Dr. Tiffany Kodak, for her substantial guidance and support while designing, implementing, and analyzing this research. I would also like to thank Raven Wood, Erin Corrigan, and Brittany Juban for their assistance with data collection.

Finally, I would like to provide a special thanks to my committee members, Dr. Jeffrey Tiger and Dr. Jason Bourret for their expertise, feedback, and contributions. 
A prompt is defined as an antecedent stimulus that controls a response (MacDuff, Krantz, \& McClannahan, 2001). Prompts are often used to teach individuals with and without disabilities skills that are not currently a part of their repertoire (MacDuff, Krantz, \& McClannahan, 2001). Prompts are used to occasion a correct response in the presence of relevant antecedent stimuli and so that the response can produce reinforcement. For example, a parent might provide a vocal prompt to "use a fork" if a child is reaching for a plate of spaghetti with her hands. Once the child picks up the fork and uses it to eat spaghetti, the parent might provide praise (e.g., "Great job using your fork!").

Multiple types of prompt-fading procedures have been successful for teaching preacademic/academic (e.g., Fisher, Kodak, \& Moore, 2007) and leisure/vocational (e.g., McKay, Weiss, Dickson, \& Ahearn, 2014) skills to individuals with developmental disabilities. Common prompt-fading strategies used in skill acquisition programs include a prompt delay, most-to-least prompting, and least-to-most prompting.

Touchette (1971) initially described a prompt delay procedure (which he referred to as time delay) in which stimulus control is transferred from the controlling prompt to the discriminative stimulus $\left(\mathrm{S}^{\mathrm{D}}\right)$ by a delay interval. Two types of prompt delays include a constant and progressive delay. A constant prompt delay (CPD) consists of a fixed amount of time (delay) between the $\mathrm{S}^{\mathrm{D}}$ and the prompt. For example, an instructor may consistently wait up to $5 \mathrm{~s}$ for the individual to respond prior to providing a prompt. A progressive prompt delay (PPD) consists of the delay being systematically increased across sessions or trials (Schuster, Gast, Wolery, \& Guiltinan, 1988). For example, the instructor may initially wait $1 \mathrm{~s}$ for a response before providing a prompt and increase the delay to $2 \mathrm{~s}$ contingent on several trials in which the individual does not respond prior to the prompt. 
There is considerable empirical support for the efficacy of CPD and PPD. For example, Schuster et al. (1988) investigated the efficacy of a 5-s CPD procedure in teaching chained responses. Results showed that all four of the adolescents diagnosed with mental retardation successful learned the chained responses, and the skills maintained at a minimum of $85 \%$ correct after three months. Cariveau, Kodak, and Campbell (2016) used a PPD to teach twenty-four novel responses to two participants with autism spectrum disorder (ASD). Their results showed that the PPD was an efficacious training procedure that produced mastery of all targeted skills regardless of the format of training (massed- or varied-trial instruction) and amount of time between instructional trials. Further, Walker (2008) reviewed and compared 22 studies that evaluated prompt delay procedures and found that PPD resulted in fewer errors to mastery and the necessity of less procedural modifications.

Another prompting procedure for skill acquisition is most-to-least prompting (MTL; Striefel \& Wetherby, 1973), which consists of more intrusive prompts at the onset of instruction. More intrusive prompts are faded to less intrusive prompts to provide opportunities for independent correct responses. Fentress and Lerman (2012) used MTL prompting with four prompting levels to teach receptive identification, imitation, matching, tacts, and receptive instructions to children diagnosed with ASD. The authors began the first trial with an instruction paired with a full physical prompt. Each correct response resulted in a less intrusive prompt provided at the beginning of the trial. If the participant was not successful with a less intrusive prompt level, the therapist went back to the previous prompt level at which the participant was successful (i.e., one level more intrusive). The same procedure was continued until the participant engaged in correct independent responses that met the mastery criterion. The results 
showed that the MTL prompting condition resulted in the fewest errors and higher performance during maintenance probes than a comparison intervention.

Least-to-most (LTM; Cronin \& Cuvo, 1979) is a third prompt-fading procedure that consists of an increasing level of intrusive prompts within a learning opportunity. The trial begins with an instruction (i.e., a vocal $\mathrm{S}^{\mathrm{D}}$; “Touch your nose.”). If the participant does not respond to the vocal instruction within a specific time period, the therapist presents a more intrusive prompt (e.g., a model prompt). If a correct response still does not occur, the therapist provides the most intrusive prompt (e.g., full physical guidance). Least-to-most prompting has also been referred to as guided compliance (e.g., Miles \& Wilder, 2009).

Researchers have compared multiple prompt-fading procedures to evaluate potential advantages of commonly used teaching methods (e.g., Cengher, Shamoun, Moss, Roll, Feliciano, \& Fienup; Libby, Weiss, Bancroft, \& Ahearn, 2008; Seaver \& Bourret, 2014). For example, Libby et al. (2008) compared MTL and LTM procedures for teaching children to build block structures. Results showed that LTM lead to the most rapid acquisition for a majority of participants, but all participants mastered the skill with fewer errors during MTL. However, their second experiment found similar acquisition for LTM and MTL when the MTL procedure included a prompt delay.

Similarly, Seaver and Bourret (2014) conducted a three-experiment study in which they compared response prompts for teaching behavior chains to participants with ASD. The first experiment consisted of a prompt-type assessment in which types of prompts (e.g., verbal, gestural, physical) were compared using a PPD with a structure-building task. The results of the first experiment were applied to a comparison of the most efficient type of prompt-fading procedure in the second experiment. The prompt-fading procedures included in the comparison 
were PPD, MTL, and LTM procedures. The authors found that the fastest acquisition occurred with LTM prompting for three participants and PPD for four participants. The results of Seaver and Bourret and Libby et al. (2008) showed that the efficiency of prompting procedures may be idiosyncratic across individuals.

When prompting procedures produce discrepant results across participants, it is important to consider other variables that may influence the decision to select and use specific prompting strategies with learners (Hanley, 2010; Kodak et al., 2016). For example, the feasibility of a prompting procedure may influence whether it is selected for use. If a prompting procedure is difficult to implement or results in reduced treatment integrity, it may not be ideal to use this intervention despite the level of efficacy and efficiency. In addition, the social validity of intervention procedures is important to consider. Procedures that are not considered socially valid by parents or participants may not be ideal to use.

Research that investigates parents' preference for different interventions may provide valuable information on procedures that are more likely to be implemented when experimenters or staff are not present. A critical piece of many clinical programs consists of training parents how to conduct behavior-analytic procedures to assist with acquisition, skill maintenance, and generalization of new skills. Parents have been trained to successfully implement several behavior-analytic procedures including discrete trial instruction (e.g., Lafasakis \& Sturmey, 2007), communication training (Ingvarsson, 2011), prompting (e.g., Miles, \& Wilder, 2009), and functional analyses (e.g., Najdowski, Wallace, Penrod, Tarbox, Reagon, \& Higbee, 2008). Behavioral skills training has been used to teach parents many of these interventions. Behavioral skills training typically consists of instruction, modeling, role play (i.e., rehearsal), and feedback. Lafasakis and Sturmey (2007) successfully used behavioral skills training to teach parents 
discrete trial instruction, and the skills generalized to novel discrete-trial programming. Although the extant literature on parent training has demonstrated the efficacy of training procedures, relatively few studies have investigated the social validity of such interventions.

Social validity refers to the extent to which an intervention is considered socially acceptable and important to the current society, and social validity is often assessed using indirect measures (e.g., rating scales). Treatment acceptability is a component of social validity that relates to the consumers (e.g., parents, teachers) perceptions and willingness to assist with of the treatment (Kazdin, 1980). For example, Davis, Reichle, and Southard (2000) measured treatment acceptability with two interventions that increased successful transition behavior. During a maintenance probe, a confederate observed transitions in the school and recorded the proportion of transitions in which each of the interventions were used. Although both interventions were efficacious and rated as acceptable by staff members, one of the interventions was implemented during a majority of the transitions. This allocation of staff responding to one intervention suggests a preference for one of the interventions that was not captured by the indirect measure.

Social validity should be further differentiated from preference. A preference is established when an individual's responding is allocated to one option more than the other available options. Preference has been evaluated in a variety of ways such as through preference assessments (e.g., MSWO; DeLeon \& Iwata, 1996) and concurrent-chains arrangements (Herrnstein, 1964). It has been suggested that training parents on multiple interventions may lead to the selection a procedure that parents will use when an experimenter or clinician is no longer present (e.g., outside the clinical setting; Gabor, Fritz, Roath, Rothe \& Gourley, 2016; Lerman, Vorndran, Addison, \& Contrucci Kuhn, 2004). 
Gabor et al. (2016) evaluated acceptability of and preference for function-based treatments for problem behavior. The parent training consisted of behavioral skills training. Parents also completed a treatment acceptability form multiple times throughout the study. Following mastery of training, experience sessions were conducted in which the parent practiced the procedures with the child. After parents achieved mastery criteria (>90\%) across all conditions, choice sessions were conducted with a concurrent-chains arrangement. The initial link of the concurrent-chains arrangement consisted of parent selection between the three interventions and a control condition, while the terminal link consisted of the parent using the selected intervention with the child.

Results of Gabor et al. (2016) indicated that two parents preferred differential reinforcement of alternative behavior, two preferred differential reinforcement (e.g., alternative and other behavior) over noncontingent reinforcement, and one parent did not show a preference for any of the intervention options. The parent that did not show a preference between interventions still showed a preference for the trained interventions over her own strategies. Nevertheless, the treatment acceptability ratings inconsistently corresponded with parent preference for intervention. For example, only one participant preferred the option she had rated as highly preferred in the pre-experience sessions. Additionally, another participant's ratings of acceptability matched the most commonly selected intervention only after experiencing the implementation of all interventions with her child. Therefore, additional research on parent preference and acceptability ratings is warranted with other interventions for which parents frequently receive training.

To our knowledge, no previous studies have compared parent preference for and treatment acceptability of prompt-fading procedures, although it has been suggested for many 
years that parent involvement in treatment plays a large role in child treatment gains and maintenance of skills (Lovaas, Koegel, Simmon, \& Long, 1973). Therefore, the purpose of the present investigation was to extend Gabor et al. (2016) to conduct an examination of parent preference hierarchies for three prompt-fading procedures commonly used during comprehensive behavioral intervention. Parents received behavioral skills training to implement all three prompt-fading procedures with high integrity. Thereafter, we conducted a concurrent-chains arrangement to measure parent preference for the prompt-fading procedures. Additionally, treatment acceptability of all procedures was measured multiple times throughout the study.

\section{Method}

\section{Participants}

Four parent-child dyads participated in this evaluation. Each parent was currently receiving comprehensive behavioral intervention from a local service provider and had no prior training with the specific prompt-fading procedures used in this comparison. Mr. and Mrs. Roberts were the parents of Henry, a 4-year old diagnosed with ASD. Mrs. Davis was the mother of Mark, a 6-year-old diagnosed with ASD. Mrs. Sullivan was the mother of Ethan, a 6-year-old diagnosed with a moderate intellectual disability and global developmental delay. Staff confederates consisted of undergraduate students enrolled as research assistants and graduate students enrolled in a master's or doctoral training program in applied behavior analysis at a local university.

\section{Setting and Materials}

Training sessions were conducted in each participant's home in a room typically used for behavior therapy or a quiet room with minimal distractions. Each room included a timer, table, chairs, data sheets, preferred items, and program materials. Only the experimenter(s), parent, and 
data collectors were present during initial training sessions. The child participant was also present during the experience sessions and choice sessions (described below).

Program materials varied depending on the child's clinical goals, and specific stimulus cards were selected for use in training based on each child's goals. Stimuli included laminated flashcards with pictures. Listener responses for item features (e.g., a stem on an apple, a trunk on an elephant) were selected as the targets for Henry and Mark. Listener responses of categories (e.g., sports, insects, art supplies) were selected as the targets for Ethan. Tangible and edible items based on a child preference assessment were also used throughout the study. A video camera was present to record sessions for data collection following sessions.

\section{Response Measurement and Interobserver Agreement}

Parent behavior. The primary dependent variable was the cumulative frequency of prompting procedure selections by the parent. A selection was defined as the parent touching the card corresponding to the respective prompting procedure and/or vocally saying his/her selection out loud. Selections were recorded during choice sessions. Data also were collected on parent implementation of the prompting procedure on a trial-by-trial basis with a checklist. Correct implementation for each step in a trial was measured by marking a plus when the step was implemented correctly, a minus when the step was implemented incorrectly or omitted, and ' $\mathrm{O}$ ' if there was no opportunity to implement the step. Any trial in which one or more steps were scored as a minus was considered an incorrectly implemented trial. For each session, the number of trials with all steps implemented correctly was divided by the total number of trials and multiplied by 100 .

Child behavior. Data were collected on correct independent responses, the prompt level required to occasion a correct response, and the child's problem behavior during each trial. 
Correct independent responses were defined as the child engaging in the target behavior specified in the protocol (e.g., touching the correct feature) or selecting the target stimulus card (i.e., selecting the stimulus that corresponded to the targeted category) within $5 \mathrm{~s}$ of the vocal instruction. The prompt level required to produce a correct prompted response during each trial was recorded by scoring the type of prompt (e.g., model) following which the correct response occurred within $5 \mathrm{~s}$. Mean sessions to mastery was calculated for each parent-child dyad by dividing the total number of sessions conducted in each procedure by the number of targets mastered with the procedure.

Problem behavior data also were collected on a trial-by-trial basis. Definitions of problem behavior were individually defined for each participant and included aggression (e.g., hitting, kicking, pinching), self-injurious behavior (e.g., head banging, hand-to-head), disruption (e.g., swiping materials off the table), negative vocalizations (e.g., screaming), vocal non-compliance (e.g., saying no), and elopement.

Staff behavior. Treatment integrity data were collected on the staff confederate's implementation of behavioral skills training for a minimum of $80 \%$ of training sessions across parents. Checklists were used to measure staff behavior. Two checklists were developed; one was for the first training session of each procedure, and the other checklist was used for all remaining training sessions. The number of steps implemented correctly was divided by the total number of steps and converted to a percentage. Staff treatment integrity was $98 \%$ (range, $94 \%$ to $100 \%$ ) for Mrs. Roberts, $98 \%$ (range, $94 \%$ to $100 \%$ ) for Mr. Roberts, $99 \%$ (range, $93 \%$ to 100\%) for Mrs. Davis, and 93\% (range 47\% to 100\%) for Mrs. Sullivan. The low session with Mrs. Sullivan represents when feedback was provided at the end of the behavioral skills training 
session instead of on a trial-by-trial basis (i.e., feedback was still provided, but at the incorrect time for that training session).

Interobserver agreement. Two trained independent observers collected data on parent behavior during training sessions or from video recordings. Interobserver agreement (IOA) was calculated using the trial-by-trial method. Following all sessions, each trial on the checklist was compared, and an agreement was defined as the two observers scoring the same behavior for all of the steps in the trial. A disagreement was defined as the two observers scoring a different behavior for one or more of the steps within the same trial. The number of trials with an agreement was divided by the total number of trials and multiplied by 100 . Data on IOA were collected for $45 \%$ to $69 \%$ of sessions for each parent. Mean IOA was $97 \%$ (range $90 \%$ to $100 \%$ ) for Mrs. Roberts, $98 \%$ (range $80 \%$ to $100 \%$ ) for Mr. Roberts, $96 \%$ (range $80 \%$ to $100 \%$ ) for Ms. Davis, and $97 \%$ (range $80 \%$ to $100 \%$ ) for Mrs. Sullivan.

A second trained observer collected data for treatment selection during the choice trials for a minimum of $44 \%$ of sessions. Mean IOA for treatment selection was $100 \%$ for all participants. Finally, a second trained observer collected data on child problem behavior and compared this to the parent's data collection during a minimum of $44 \%$ of choice sessions. Following sessions, each trial on the parent data sheet was compared to the observer's data collection on integrity. An agreement occurred when both observers scored the presence or absence of problem behavior in an identical manner in the trial. Mean IOA was 99\% (range 90\% to $100 \%$ ), $99 \%$ (range $90 \%$ to $100 \%$ ), $96 \%$ (range $80 \%$ to $100 \%$ ), and $98 \%$ (range $80 \%$ to $100 \%$ ) for Mrs. Roberts, Mr. Roberts, Mrs. Davis, and Mrs. Sullivan, receptively.

\section{Experimental Design}


A modified multiple probe across interventions design was used for training with each parent. Initial baseline probes of each procedure were conducted prior to training each procedure. The sequence of training consisted of LTM, PPD, MTL. Baseline probes also were conducted after training each prompting procedure to ensure that the skill maintained before moving into experience sessions with the child.

A concurrent-chains arrangement was used to show experimental control for the choice sessions. The initial link consisted of the parent's selection of one prompting procedure. The terminal link consisted of the parent conducting a session with his/her child using the selected prompting procedure.

\section{Pre-Assessments, Tests, and Stimuli}

Prompt-type assessment. A brief assessment was conducted by the experimenter with each child prior to the start of the investigation to evaluate the type of prompt to which each child would consistently respond correctly. The stimuli used within this assessment were related to the child's clinical goals but were not the targets included in other conditions. During 10-trial sessions, the experimenter presented a horizontal array of three stimuli to the child, and the position of the target stimulus was randomized across trials. The experimenter delivered the vocal $\mathrm{S}^{\mathrm{D}}$ and immediately provided a model prompt. Praise and a preferred tangible were provided for correct responses to the model prompt. If the child engaged in an error or no response to the model prompt, a physical prompt (i.e., hand-over-hand guidance) was provided. All three child participants engaged in a correct response to the model prompt during $100 \%$ of trials for two consecutive sessions after four or fewer assessment sessions.

Pre-tests. The stimuli selected for inclusion in the investigation were based on each child's current skill deficits and treatment goals. A pre-test was conducted to identify stimuli to 
which the child participant did not respond correctly. Pre-test sessions included 9 to 12 trials, and each potential target was presented three times. The experimenter did not provide prompts or reinforcement during trials, although mastered tasks were interspersed approximately every two trials. Correct independent responses to mastered tasks produced praise and access to a preferred item for 20 to $30 \mathrm{~s}$. Stimuli to which the participant responded correctly during less than $33 \%$ of the trials were included in training sessions.

Stimulus sets. All stimuli were taught in a massed-trial format, although the type of skills varied by child participant (see materials section). Massed-trial instruction consisted of presenting the same discriminative stimulus for each trial during a session, although multiple targets were incorporated into a single session (e.g., categories). For example, during training of categories, the $\mathrm{S}^{\mathrm{D}}$ "animal" was presented on all 10 trials, but two different exemplars of animals were targeted within the session (e.g., monkey, penguin). During category training, distractor stimuli were included in the array, and their location varied during each trial. Additionally, for feature training, two exemplars of each target were presented within a session (i.e., two pictures of different elephants with the target 'trunk'). Different stimuli were assigned to each prompting procedure and each phase of training (i.e., experience and choice sessions).

A stimulus was considered mastered when the child engaged in a correct independent response on at least $90 \%$ of trials in a session, with the additional requirement that the first trial of the session must be correct (Grow, Carr, Kodak, Jostad, \& Kisamore, 2011). Following mastery of each set of stimuli, training on a new stimulus was introduced. New targets were also introduced following three consecutive sessions with a stable or decreasing trend. Training of stimuli continued until sessions of the current-chains arrangement was completed. The purpose of conducting massed-trial instruction and requiring only one session with high levels of correct 
responding to reach the mastery criterion was to introduce novel stimuli frequently, which provided ample opportunities for each parent to practice implementing all prompts within each the prompting procedures.

\section{Preference Assessment}

At the start of each appointment, a brief multiple stimulus without replacement (MSWO) preference assessment was conducted by one of the experimenters (Carr, Nicolson, \& Higbee, 2000). The top two items were included throughout the training session. If at any point the child does not accept or consume the item, another choice was offered prior to the next trial. If the child vocally requested an alternative item, the parent provided the requested item (if available).

\section{Prompting Procedures}

Three different prompt-fading procedures were taught to each parent. The procedures were taught to all parents in the same order, and each procedure was taught to mastery before introducing the next one. This order included LTM, PPD, and MTL. During all procedures, if the child engaged in problem behavior, the parent immediately (within $2 \mathrm{~s}$ ) moved up one level of intrusiveness from the prompt level in the current trial (e.g., Giannakakos et al., 2016).

Least-to-most prompts (LTM). The prompting hierarchy consisted of providing the least intrusive prompt needed for a correct response at the onset of every trial. That is, the prompting hierarchy consisted of a (a) vocal instruction, (b) model prompt, and (c) physical prompt. Refer to Appendix A for a flow chart of the LTM prompting procedure. A vocal prompt was provided for the first trial presentation of a stimulus. If the child participant made an error or did not respond within $5 \mathrm{~s}$, the next intrusive prompt was provided. The parent moved up the prompting hierarchy with $5 \mathrm{~s}$ response intervals between prompts until the child engaged in a correct response. If the child did not comply with the physical prompt (e.g., the child resisted 
guidance to touch a stimulus in the array), the parent discontinued the physical prompt after $5 \mathrm{~s}$, no reinforcement was provided, and the next trial was initiated. All correct responses were reinforced with praise and a tangible item on a Fixed Ratio (FR) of 1 schedule.

Progressive prompt delay (PPD). The prompting hierarchy included a prompt provided at a (a) 0-s delay, (b) 2-s delay, and (c) 5-s delay. A model prompt was used at each prompt delay interval. Refer to Appendix B for a flow chart of the PPD procedure. The first trial of a stimulus began with an immediate prompt (i.e., 0 -s delay). Following one trial with a 0 -s delay and a correct prompted response, the time between the onset of the trial and a prompt was faded to $2 \mathrm{~s}$. If the participant responded correctly prior to a prompt at the 2 -s delay, the prompt was faded to a 5-s delay. Criteria to advance and decrease a prompt level was based on a response in each trial; prompts were faded following an independent correct response. If a correct prompted response occurred, the prompt delay moved back to the previous delay level (e.g., decrease from a 5-s delay to a 2-s delay). All correct responses were reinforced with praise and a tangible on a FR1 schedule.

Most-to-least prompts (MTL). This prompting hierarchy consisted of a (a) physical prompt (i.e., hand-over-hand guidance), (b) model prompt (i.e., pointing to the correct stimulus), and (c) vocal instruction. Refer to Appendix C for a flow chart of the MTL procedure. The first presentation of a stimulus included a physical prompt; thereafter, prompt fading began. Prompts were faded based on the child's response. That is, prompt-fading consisted of a reduction in the level of intrusiveness of a prompt following each correct response, as conducted by Severtson and Carr (2012). If the child did not engage in a correct response with the first prompt utilized for a trial, the instruction was repeated and a prompt one level higher was provided until the parent reached the most intrusive prompt or a correct prompted response occurred. For example, 
if the parent began a trial with a vocal instruction but the child made an error, a model prompt was utilized. If the child made another error following the model prompt, a physical prompt was provided. If multiple prompts were used within a trial, the following trial still began with the prompt type that was one level less intrusive than the prompt necessary to occasion a correct response. As in LTM, the parent attempted to provide the physical prompt for a total of $5 \mathrm{~s}$ if the child resisted the physical prompt. If the physical prompt did not produce a correct response, no reinforcement was provided, and the next trial was initiated. All correct responses were reinforced with praise and a preferred item on a FR1 schedule.

\section{Parent Training}

Sessions occurred one to four days per week, depending on the parent's schedule. The duration of all appointments was approximately 1 to 1.5 hours. The sequence of training procedures consisted of behavioral skills training, experience sessions, and choice sessions. The criteria to advance from behavioral skills training consisted of all trials in the role-play with $100 \%$ accuracy for one session. Additionally, any baseline probes following training were required to maintain at $90 \%$ integrity, otherwise additional behavioral skills training sessions were implemented for that procedure. The criteria to advance to choice sessions consisted of three consecutive experience trial sessions with at least $90 \%$ integrity (i.e., one of each prompting procedure). See Appendix D for a sequence of training procedures and criteria for advancing to and from the different training steps.

Pre-training. The parent was shown three videos (one of each prompt-fading procedure)

of an experimenter implementing a session of each prompting procedure with a staff confederate. Each video showed a 6-trial session with examples of all prompt types, responding to problem behavior, and securing the child's attention to materials. The staff confederate followed a 
simulated child script for each prompt-fading procedure. Immediately after viewing each video, each parent was instructed to complete the treatment acceptability forms for the prompting procedure shown in the video.

Behavioral skills training. The experimenter taught the parents to implement all three prompt-fading procedures using behavioral skills training. The order of training for each prompting procedure was kept consistent across parent-child dyads (i.e., LTM, PPD, MTL). Training sessions were conducted without the child present. Parents received vocal instructions on how to respond to problem behavior. They were told to keep a neutral facial expression, not attend to problem behavior unless the child's safety was at risk, and to increase the intrusiveness of the prompt by one level immediately following problem behavior.

At the start of each training session, the parent was given a card that briefly described the prompting procedure and steps to implement it (see Appendix E). Next, the experimenter went through the steps of the procedure and showed the video model of each step of the prompting procedure while the parent observed. Opportunities for questions were permitted throughout the video. Following the video model, the experimenter role-played the procedures with the parent; the experimenter served as the child, and the parent took the role of the instructor. During roleplay, the parent implemented a 10-trial session using the prompting procedure shown in the video model. The experimenter followed a script that specified how to respond during each trial, trials in which the experimenter was to engage in problem behavior, and trials in which the experiment was not to attend to stimuli appropriately. See Appendix F for an example script of each condition.

During the first role-play session, the experimenter provided positive and corrective feedback to parents following each trial. This feedback consisted of two praise statements and 
one corrective comment. Thereafter, positive and corrective feedback was provided at the end of each 10-trial session. Training was considered complete for a prompting procedure when the parent implemented all trials in the role-play with 100\% accuracy for one session. See Appendix $\mathrm{G}$ for the guidelines experimenters used to provide feedback to the parents.

\section{Experience Sessions}

Parents practiced each the prompting procedure in a randomized order with his/her child. Consistent with Gabor et al. (2016), parents had access to the cards used during the training that described the prompting procedure, and these cards were provided prior to and during sessions. The experimenter did not interact with the parent or child during experience sessions except to observe and collect data. For example, the experimenters did not provide comments on incorrect responses to avoid creating a bias for the prompting type that the parent implemented with the highest accuracy. Vocal feedback was only provided at the parent's request (e.g., asking a question).

The mastery criterion to move from experience sessions to the choice sessions was three consecutive sessions (i.e., one of each condition) with at least $90 \%$ integrity (9 out of 10 trials with all steps correct). If treatment integrity fell below $90 \%$ for any of the prompting procedures, training was re-implemented for all three procedures (i.e., until each prompt procedure reached $90 \%$ ). Parents completed a session of all three prompting procedures prior to moving back into re-training, and they were not told which intervention condition resulted in the necessity for retraining. Re-training consisted of additional exposures to the instructions card paired with behavioral skills training.

\section{Choice Sessions}


A concurrent-chains arrangement was used to assess parent's preference for the prompting procedures using procedures described by Gabor et al. (2016). The experimenter presented cards of the three prompting procedures in an array. Following a selection, the card remained on the table and the terminal link was initiated. The terminal link consisted of the parent implementing the selected prompt-fading procedure with the child for a 10-trial session.

The parent's high-preference (HP) prompting procedure was identified once one procedure was selected six more times than any other procedure (Slocum \& Tiger, 2011). Sessions continued until the HP procedure was identified or 20 choice sessions were conducted with no preference (Luczynski \& Hanley, 2009). Following identification of the HP prompting procedure, the card corresponding to the HP procedure was be removed from the array and the concurrent-chains procedure was conducted again with the two remaining stimuli in order to identify the moderately preferred procedure (MP). The second concurrent-chains arrangement ended based on the same criteria specified for the HP. Sessions were terminated following identification of the two most preferred prompting procedures.

\section{Treatment Acceptability}

A modified TEI-SF (Kelley, Heffer, Gresham, \& Elliot, 1989) was used to measure parent treatment acceptability (See Appendix H). The form consisted of eight questions that parents scored on a 5-point Likert scale, ranging from strongly disagree to strongly agree. From the original TEI-SF, two questions were omitted because they were not specifically related to the prompting procedures. An additional item also was added to measure whether the parent would recommend the procedure to others. The form was given to each parent prior to the start of training (e.g., following pre-training videos), immediately after mastery of training with the staff confederate for each prompt type (i.e., behavioral skills training), and following the choice 
sessions. Treatment acceptability scores were measured throughout the study to evaluate whether a specific amount of exposure to procedures altered acceptability scores and to determine the similarity in procedure scores between the TEI-SF and the concurrent-chains procedure.

An acceptability criterion rating scale also was given to parents at the same three times throughout the study (Appendix I). This form had the parents rate each prompt procedure, individually, on a scale of $0-100$. It also asked the parent to identify a point at which they do not consider interventions to be acceptable (i.e., they would not want to implement the intervention or would not want others to implement it with their child).

\section{Results}

\section{Parent Integrity}

Results of treatment integrity for Mrs. Roberts, Mr. Roberts, Mrs. Davis, and Mrs. Sullivan are displayed in Figures 1, 2, and 3, and 4, respectively. Mrs. Roberts met mastery criteria for all promoting procedures in two or less training sessions and maintained high fidelity with intervention implementation in probes following training and experience sessions (Figure 1). She also maintained high integrity for all procedures throughout the choice sessions.

Mr. Roberts met the mastery criterion for training in five or less training sessions across prompting procedures (Figure 2). Least-to-most took three training sessions, PPD took five sessions, and MTL took two sessions. Mr. Roberts had relatively high integrity during choice sessions; however, during the second concurrent-chains arrangement, his treatment integrity was more variable (range, $50 \%$ to $100 \%$ for PPD and $70 \%$ to $100 \%$ for MTL).

Mrs. Davis met mastery criteria for LTM and PPD in two or fewer sessions, and she initially mastered MTL within baseline. Although she met initial mastery criteria quickly, she was required to go back into behavioral skills training two times due to integrity errors within 
experience sessions with her son. She met mastery criteria for experience sessions during her third practice opportunity. She then maintained high integrity during choice sessions (Figure 3).

Mrs. Sullivan met mastery criterion for LTM and PPD in four training sessions each. She initially met the mastery criterion for MTL within baseline, although in a later probe, her integrity fell below $90 \%$ and she was required to receive training for MTL. During experience and choice sessions, her integrity maintained at high levels (Figure 4.).

\section{Choice Sessions}

Results of Mrs. Robert's choice sessions are shown in Figure 5. The LTM procedure met the criteria for the HP intervention, and MTL met the criteria for the MP intervention. Initially, Mrs. Roberts selected each of the interventions a minimum of two times prior to consistently selecting one procedure. Once LTM was removed from the array, she allocated all of her responding to MTL and did not select PPD again.

Figure 6 shows the cumulative selections of prompting procedures for Mr. Roberts in which LTM was identified as the HP intervention and MTL was identified as the MP intervention. He also selected each intervention a minimum of three times prior to allocating his selections to LTM. After LTM was removed, he alternated selections of MTL and PPD for the first 10 choice sessions, after which he selected MTL only.

Mr. Davis selected LTM as HP intervention and MTL and MP intervention (Figure 7). She rapidly demonstrated preference for LTM after sampling each of the other procedures only twice. She allocated all of her responding to MTL within the second concurrent-chains arrangement, similar to Mrs. Roberts.

Similar to other participants, Mrs. Sullivan followed the same hierarchy in which she selected LTM as the HP intervention and MTL as the MP intervention (Figure 8). Mrs. Sullivan 
also engaged in some initial sampling of each of the procedures. Overall, each parent chose LTM as their HP intervention within the concurrent-chains arrangement. The MTL procedure was consistently identified as the MP intervention, and PPD was always identified as the least preferred intervention.

Table 1 indicates overall data for parents and their children during choice sessions. Children mastered at least two targets in all of the prompting procedures with three of the four parents (Mrs. Roberts, Mr. Roberts, and Mrs. Davis). The percentage of sessions with problem behavior varied across children, but it was the highest in the PPD condition for three of the four participants (Henry with Mr. and Mrs. Roberts, and Mark with Mrs. Davis).

With Mrs. Roberts, Henry's most efficient procedure (i.e., the procedure that resulted in the fewest sessions to mastery) was LTM (1.25 sessions per stimulus), followed by MTL (1.33 sessions per stimulus) and PPD (2 sessions per stimulus). In comparison, the most problem behavior occurred within PPD, followed by LTM and MTL, respectively. With Mr. Roberts, Henry's most efficient condition was MTL (1.5), closely followed by LTM (1.67) and then PPD (4). Similar to Mrs. Roberts, Henry also engaged in the most problem behavior during PPD with Mr. Roberts. Overall, PPD resulted in the lowest mean sessions to mastery but the highest percentage of sessions with problem behavior for Henry with both of his parents

For Mrs. Davis, Mark mastered sixteen total targets. Mean sessions to mastery was similar across procedures. More specifically, PPD and MTL produced identical mean sessions to mastery (1 session per stimulus) closely followed by LTM (1.33 sessions per stimulus). Mark’s percentage of sessions with problem behavior was lowest for LTM followed by MTL and PPD, respectively. Like Henry, PPD was associated with the most problem behavior and was the least preferred parent intervention. 
Ethan mastered a total of ten targets with Mrs. Sullivan. Unlike the other participants, Ethan did not master any targets in PPD, despite the fact that Mrs. Sullivan conducted three sessions of this procedure. Mean sessions to mastery was lowest for LTM (1.5 sessions per stimulus) followed by MTL (6.5 sessions per stimulus). Similar to Henry's responding with Mrs. Roberts, LTM had the lowest mean sessions to mastery with LTM and was the HP procedure for each of them. However, contrary to the other participants, the highest percentage of problem behavior occurred during LTM followed by MTL and PPD, respectively. Nevertheless, Ethan engaged in the lowest amount of problem behavior across procedures in comparison to the other child participants.

\section{Treatment Acceptability}

Treatment acceptability was measured at three points in time during the study for the four parents are shown in Figures 9 to 12. Beginning scores were obtained before training, middle scores were obtained after mastery with a staff confederate during behavioral skills training, and end scores were obtained after completion of choice sessions and implementing instruction with the child.

Three of the four participant's final TEI-SF acceptability scores matched (or tied with) his/her selections in the choice sessions. Said another way, the last acceptability scores corresponded with the preference hierarchy established in the choice sessions. However, three of the four participants changed their TEI-SF scores and/or acceptability criterion rating scale in some way from the beginning to the end of the study. Thus, indirect acceptability measures appeared to fluctuate throughout the study, suggesting that subjective ratings of acceptability may not be a reliable predictor of parent preference for intervention. 
Mrs. Roberts (Figure 9) initially provided the highest TEI scores for the MTL and LTM procedures, which was consistent with her final TEI scores. On the acceptability criterion rating scale, Mrs. Roberts initially provided identical ratings for each of the interventions. Following behavioral skills training with the confederate, her rating of PPD dropped to the threshold of acceptability (i.e., the point at which anything below it would not be considered acceptable). After completing the choice sessions, her ratings directly corresponded to her hierarchy in the concurrent-chains arrangement. Overall, she showed some variability in her acceptability scores and ratings of procedures across points in time.

Mr. Roberts provided the highest scores for MTL and LTM in his beginning TEI-SF. This score was inconsistent with the acceptability criterion rating scale in which he rated MTL the highest (Figure 10). With the acceptability criterion and rating scale, Mr. Roberts consistently rated MTL the highest across all points in time (beginning, middle, and end). In the middle acceptability criterion rating scale, his score for PPD was below his acceptability threshold, yet PPD had the second highest score in the TEI-SF. In the final rating scale, he rated MTL the highest which was inconsistent with his most preferred intervention identified in the concurrentchains arrangement. Overall, for Mr. Roberts, there were some inconsistencies in how he rated the same intervention at the same and various points in time, based on the manner in which acceptability was assessed (i.e., TEI-SF or acceptability criterion rating scale).

At the beginning, Mrs. Davis initially provided the lowest score for LTM in the TEI-SF, and MTL tied with PPD as obtaining the highest scores (Figure 11). In the middle TEI-SF, her scores were all within one point of each other. During her final TEI-SF, she provided the highest possible scores of LTM and MTL. Mrs. Davis's acceptability criterion rating scale followed a similar pattern as her TEI-SF scores. For example, she initially rated MTL the highest, but 
changed her highest rating to LTM during the end rating scale. During the middle and end acceptability criterion rating scale, her ratings directly corresponded to her preferences from the concurrent-chains arrangement.

During the beginning TEI-SF, Mrs. Sullivan provided the highest scores for LTM and MTL, and PPD had the lowest score (Figure 12). During the end TEI-SF, LTM had the highest score, followed by MTL and PPD, respectively, which was consistent with her preferences from the concurrent-chains arrangement. With the acceptability criterion rating scale, Mrs. Sullivan initially rated MTL the highest followed by LTM and PPD. However, Mrs. Sullivan's end rating scale followed a similar pattern to her TEI-SF in which the highest-to-lowest ratings were provided for LTM, MTL, and PPD, respectively. Consistent with Mr. Roberts, her rating on the middle rating scale was below her acceptability threshold, although this rating increased above the threshold during the end rating scale. Overall, consistent with Mrs. Davis and Mrs. Roberts, Mrs. Sullivan's final acceptability criterion rating scale order directly corresponded to her concurrent-chains arrangement preferences.

\section{Discussion}

Consistent with Gabor et al. (2016), the results of this study support utilizing objective measures to evaluate parent preference and acceptability for behavioral interventions. Objective measures of parent preference (i.e., choice sessions in the concurrent-chains arrangement) identified a HP and MP intervention for each participant. Although the same hierarchy of preferences (i.e., LTM, MTL, PPD) in the concurrent-chains arrangement were also shown in three of the four parents' end acceptability criterion rating scales and TEI-SF scores, correspondence in TEI-SF scores across points in time was relatively low. In addition, correspondence between TEI-SF scores and the acceptability criterion rating scale also were 
variable across points in time. Observed variability in parents' TEI-SF scores across points in time is consistent with Gabor et al. (2016) and may suggest that providing procedural descriptions of interventions or allowing parents to observe a session of each intervention prior to completing the TEI-SF does not result in scores that accurately reflect their acceptability of and preference for an intervention. Furthermore, training should include more than just practice with a confederate to promote accurate identification of preference and acceptability for an intervention.

Previous evaluations of child preference for intervention show idiosyncratic differences in preferred intervention procedures (e.g., Kodak et al., 2016). However, the results of the current investigation showed consistency in parent preference for prompting procedures. All four parents selected LTM as their HP intervention and MTL as their MP intervention. Although the preference order was clear across all parents, the behavioral mechanism behind this selection are not fully understood. There are multiple variables that may play a role in acceptability of and preference for interventions, such as ease of procedures or response effort, problem behavior during intervention, efficacy of intervention with the child, and exposure to the procedure (Miltenberger 1990; Reimers et al., 1987). Thus, examination of these and other variables in the current study may provide insight into the variables that influenced parent preference.

It is possible that the ease of intervention or complexity influenced parent preference and acceptability ratings (e.g., Elliot, 1988). For example, interventions that require more effort or have more steps or components could be rated differently than lower-effort interventions. All of our prompting procedures included overlapping components. That is, all three procedures had a hierarchy of prompts, scheduled time periods between prompts, and rules related to moving to the next prompt following an error or problem behavior. Nevertheless, there were some 
important distinctions between the interventions. For example, LTM was the only intervention that began with an opportunity for an independent response on every trial. In comparison, a proportion of trials of MTL and PPD included immediate prompts. Some of the comments on the acceptability forms relate to this point. For example, Mrs. Sullivan said "LTM gave my child the most independent opportunity to achieve a correct response, and if he was unsuccessful, it aided him in learning the correct response without too much frustration." She similarly remarked that she “didn't like that he wasn't first given an independent opportunity to achieve the correct response" in MTL. Thus, some parents may have considered LTM to be a less effortful intervention, because they did not have to arrange immediate prompts during a proportion of trials.

Similarly, MTL and PPD involved variations in prompts across trials depending on the child's response in preceding trials. For example, if the child made an error in a trial of PPD, the next trial included a shorter delay to a prompt. Similarly, in MTL, the next trial included a prompt one level less intrusive then what occasioned a correct response. Comments on the acceptability forms also related to this point. For example, during the final acceptability criterion rating scale, Mrs. Roberts said "LTM is easy to use, you know where you will always start from, and has the least contact/touch with the child." In regard to PPD, she said the procedure was "way too much to keep track of." For MTL, she said, "I didn't like the 'do' prompt," which was the term associated with the physical prompt during training. Mrs. Sullivan said that PPD "was frustrating and didn't follow an easy pattern." These comments were similar to those of other participants. For example, when describing MTL, Mrs. Davis said, "I like this as it is effective, but it starts out so 'hands-on' and he didn't need that to master these." She also provided multiple comments regarding confusion about altering prompts across trials with the PPD and 
MTL procedures. These comments may suggest that using data to guide changes to the delay to a prompt or type of prompt across trials may be more effortful. Thus, it is possible that the effort of implementation of the procedures influenced parent selection of LTM as their most-preferred intervention.

It is also possible that differential levels of problem behavior across procedures may influence parent preference for or acceptability of a procedure (Reimers \& Wacker, 1992). In the present investigation, problem behavior differed across procedures, and parents sometimes preferred interventions that had lower levels of problem behavior (e.g., Mrs. Davis preferred LTM). There were a higher percentage of sessions with problem behavior during PPD for three of the four parents' choice sessions, and this was the least preferred intervention for all four parents. Problem behavior was the lowest in MTL for two of the four parents (Mr. and Mrs. Roberts), although it was the lowest in LTM for Mrs. Davis and PPD for Mrs. Sullivan. Nevertheless, problem behavior occurred in all of the procedures for three of the four parents (Mrs. Roberts, Mr. Roberts, Mrs. Davis) and two of the three procedures for Mrs. Sullivan. Our results are consistent with Gabor and colleagues (2016), such that a parent did not reliably show a preference for an intervention based on the level of problem behavior. Although, problem behavior did not reliability predict all preferences, Mr. Robert's ratings and scores may have been influenced by this dimension. During his end acceptability criterion rating scale, he said, "I think MTL is the most effective and the child will not engage in problem behavior. With more practice, I found the child could learn more without problem behavior." His comments are consistent with data on MTL, in which his child had the lowest percentage of sessions with problem behavior. Researchers could more fully investigate this variable by measuring problem behavior as a rate rather than measuring the occurrence or non-occurrence of problem behavior 
in each session. In addition, researchers might consider the magnitude (e.g., severity) of problem behavior as a dimension of problem behavior that could influence preference for interventions.

Efficacy of intervention is another variable that could influence preference for intervention. In the present investigation, all three interventions were efficacious for two of the three children (Henry with both Mr. and Mrs. Roberts, and Mark with Mrs. Davis), and two of the three prompting procedures were efficacious for Ethan. Thus, measures of efficiency (i.e., sessions to mastery) also were calculated for each child participant. However, parents did not consistently prefer the most efficient intervention; lowest mean sessions to mastery was only predictive of preference for two of our four parents (Mrs. Roberts and Mrs. Sullivan). Alternatively, MTL had the lowest mean sessions to mastery for Mrs. Davis, and MTL and PPD were tied at the lowest mean sessions to mastery for Mr. Roberts. Although some parents selected a procedure that was efficacious but had a higher mean session to mastery, multiple anecdotal reports suggest that this variable could be a factor that partially influenced their preference for an intervention. For example, three of our four parents reported that they waited to 'identify' their preference in the concurrent-chain arrangement until they saw that each procedure was efficacious and resulted in mastery of some target(s) for their child.

In the present investigation, we did not vary the order of exposure to training procedures. However, the number of behavioral skills training sessions necessary for parents to meet the established mastery criterion in their preferred intervention (LTM) was not substantially lower in comparison to the other two procedures, and all parents mastered each procedure relatively quickly. For example, Mrs. Sullivan required four training sessions for LTM, four training sessions for PPD, and two training sessions for MTL. Similarly, Mrs. Roberts required one training session to reach mastery for both LTM and MTL and two training sessions to master 
PPD. Furthermore, two of our parents initially met the mastery criterion for MTL in baseline, yet this was not their most preferred procedure. It is possible that our method minimized the effects of order of training or exposure to intervention on preference for a procedure, though. To control for differences in exposure to intervention, we took multiple precautions. For example, if one procedure fell below 90\% integrity in an experience session, we returned to training for all three procedures. Thus, actual exposure to intervention varied by no more than a few, initial training sessions. To eliminate this variable in future studies, researchers could consider having the same number of training sessions across conditions and conducting additional sessions of training beyond the mastery criterion in order to equate exposure across interventions. Similarly, in the present investigation we kept the order of training the same across parent-child dyads, consistent with the procedures of Gabor et al. (2016). Results indicated that each of the parents preferred the procedure that they learned first. Due to this potential limitation, future studies could counterbalance the order of training to determine whether the order of exposure to interventions influences preference.

The present investigation has other potential limitations. First, the number of sessions necessary for some parents to demonstrate a preference for a prompting procedure during the choice sessions may be considered a limitation. One reason this may have occurred is that parents sought more practice opportunities with their children prior to identifying their preferences. More specifically, practice with a staff confederate may not be sufficient to establish preference if parents' preference is influenced by how their children respond to these procedures. Future researchers could arrange more experience (practice) sessions with parents and their child prior to conducting the choice sessions. A second potential limitation is that we did not allow parents to indicate a preference for an alternative procedure not directly taught as part of the 
study (i.e., selection of a 'none' card). Additional studies could compare parent preference for procedures directly taught in an investigation to the procedures they implemented with their child prior to the study. Another consideration for future research is to compare parent preference for other prompts, such as no-no prompts (e.g., Leaf \& McEachin, 1999), and other skill-acquisition methods (e.g., forward chaining, shaping).

There may be other, unknown variables influencing parent preference for intervention. Further investigation of parent preference is warranted to determine the aspects of LTM, or other procedures, that result in a preference (e.g., allowing children the opportunity to engage in many independent responses opposed to providing immediate prompts). In addition, replications of parent preference for prompting procedures could be conducted to determine the consistency of preference for a specific prompting strategy as shown in our current results. Similar to the results of the present investigation, Lerman et al. (2004) found that teachers often reported being the least comfortable with conducting time-delay procedures (e.g., PPD) compared to LTM and MTL. Clinicians and researchers may find it valuable to conduct more research in order to evaluate why PPD was the least preferred prompting procedure or if making modifications to some of these procedures may alter preference (e.g., changing the delay to a prompt between sessions instead of on a trial-by-trial basis). Identification of relevant variables that consistently affect parent preference for intervention will help researchers design new interventions and alter current interventions to maximize the likelihood that parents maintain use of the intervention following training.

In summary, the results of the present investigation suggest that clinicians should not rely solely on indirect acceptability measures of interventions. If the terminal goal of identification and use of a prompting procedure for a client is for the parent to implement the intervention, 
clinicians should collect objective data on preference for and acceptability of procedures after the parent has the opportunity to implement the procedure in the natural environment with the learner. Continued research on the variables of these procedures that impact preference for interventions will assist with providing the most socially valid and efficacious skill-acquisition procedures to the clients that we serve. 
Table 1.

Choice Session Information for Each Parent-Child Dyad

\begin{tabular}{|c|c|c|c|}
\hline & LTM & PPD & MTL \\
\hline \multicolumn{4}{|l|}{ Mrs. Roberts } \\
\hline Mean sessions to mastery & 1.25 & 2 & 1.33 \\
\hline Number of targets mastered & 8 & 2 & 6 \\
\hline Percentage of sessions with PB & 50 & 75 & 25 \\
\hline \multicolumn{4}{|l|}{ Mr. Roberts } \\
\hline Mean sessions to mastery & 1.67 & 4 & 1.5 \\
\hline Number of targets mastered & 6 & 2 & 10 \\
\hline Percentage of sessions with PB & 30 & 50 & 20 \\
\hline \multicolumn{4}{|l|}{ Mrs. Davis } \\
\hline Mean sessions to mastery & 1.33 & 1 & 1 \\
\hline Number of targets mastered & 6 & 2 & 8 \\
\hline Percentage of sessions with PB & 62 & 100 & 75 \\
\hline \multicolumn{4}{|l|}{ Mrs. Sullivan } \\
\hline Mean sessions to mastery & 1.5 & N/A & 6.5 \\
\hline Number of targets mastered & 8 & 0 & 2 \\
\hline Percentage of sessions with PB & 25 & 0 & 8 \\
\hline
\end{tabular}

Note. $\mathrm{PB}=$ problem behavior. 


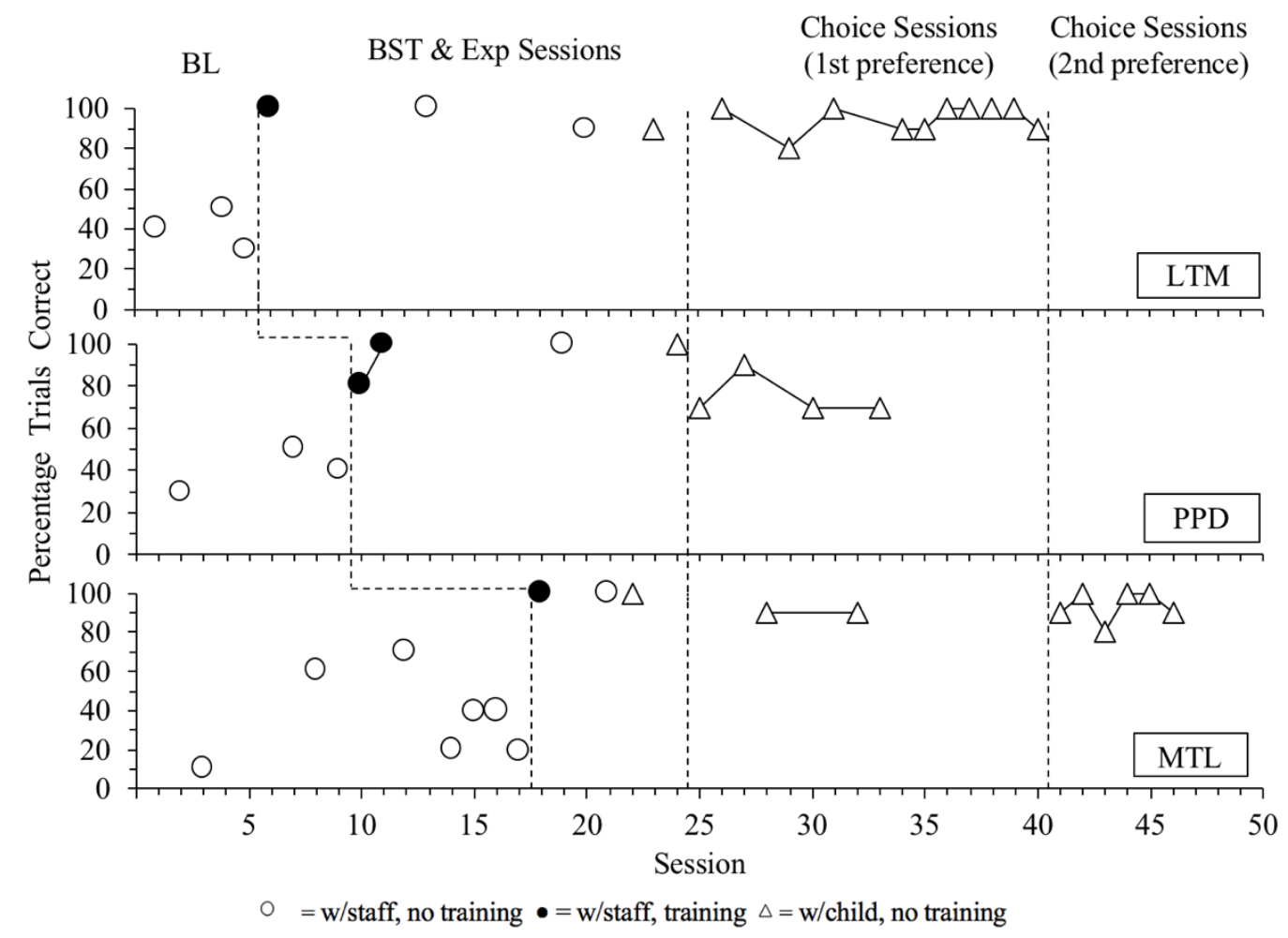

Figure 1. Parent integrity results for Mrs. Roberts during behavioral skills training, experience sessions, and choice sessions. Open points represent sessions without programmed training and feedback, while filled data points represent training sessions. 


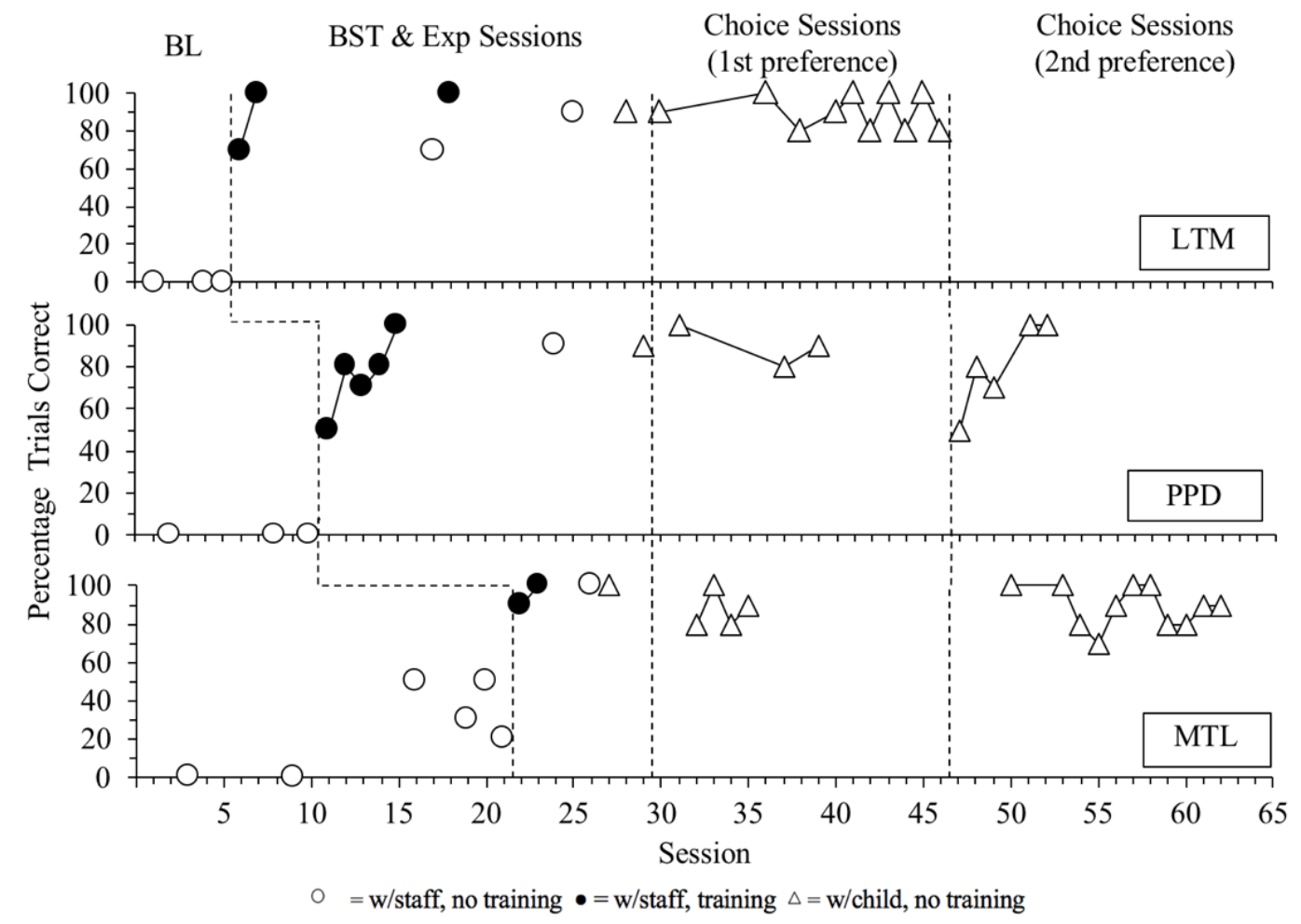

Figure 2. Parent integrity results for Mr. Roberts during behavioral skills training, experience sessions, and choice sessions. Open points represent sessions without programmed training and feedback, while filled data points represent training sessions 


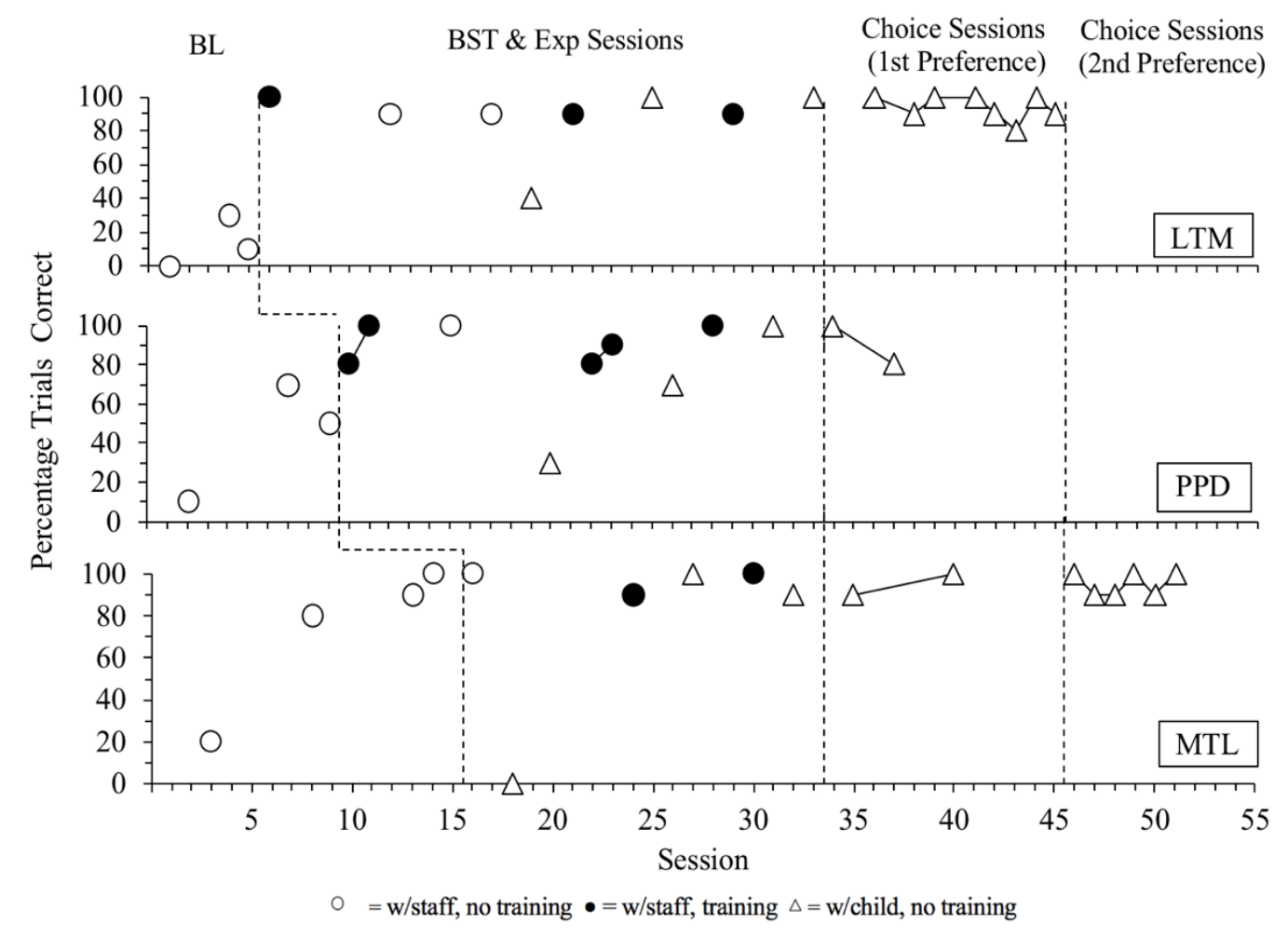

Figure 3. Parent integrity results for Mrs. Davis during behavioral skills training, experience sessions, and choice sessions. Open points represent sessions without programmed training and feedback, while filled data points represent training sessions 


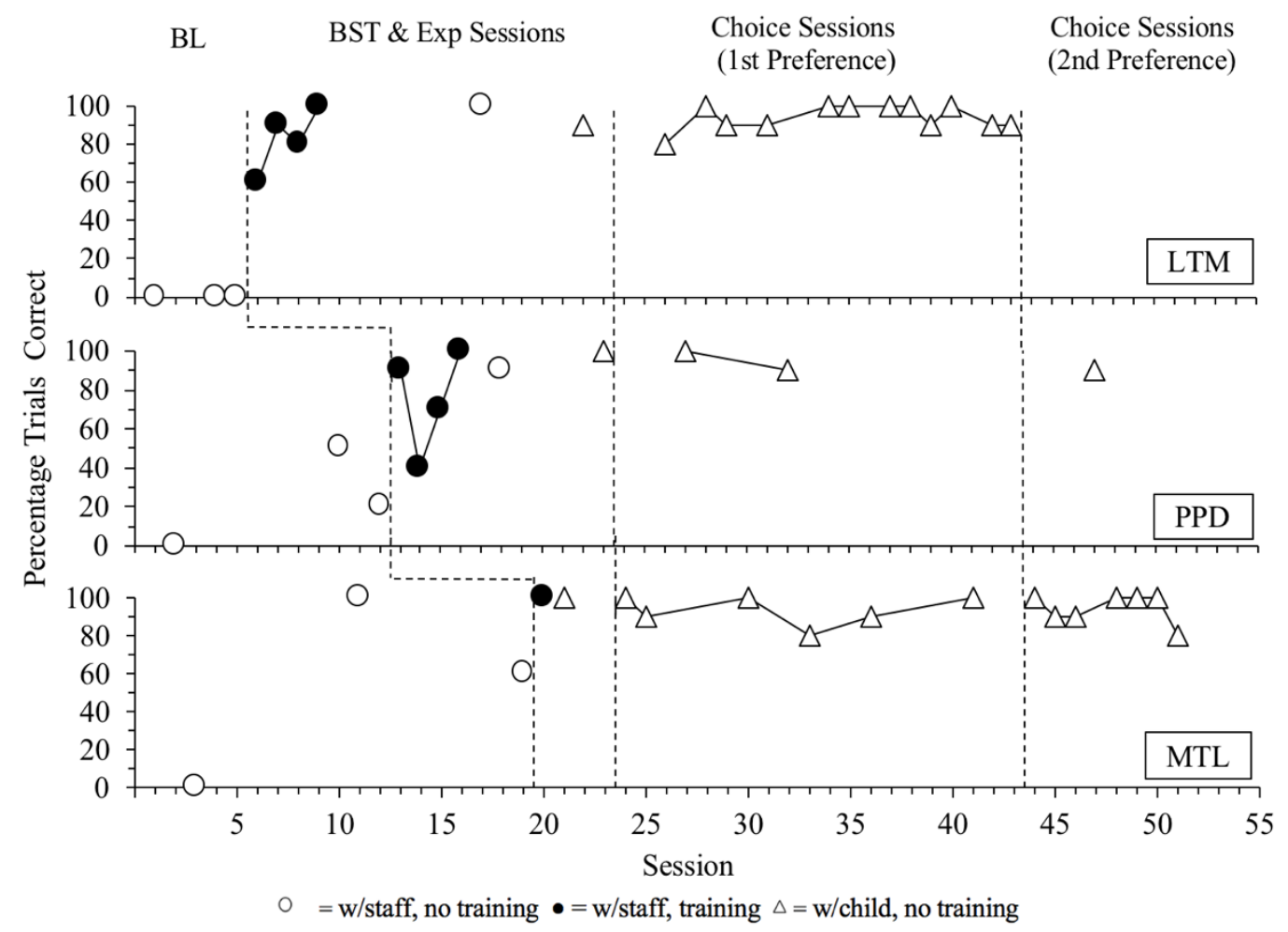

Figure 4. Parent integrity results for Mrs. Sullivan during behavioral skills training, experience sessions, and choice sessions. Open points represent sessions without programmed training and feedback, while filled data points represent training sessions 


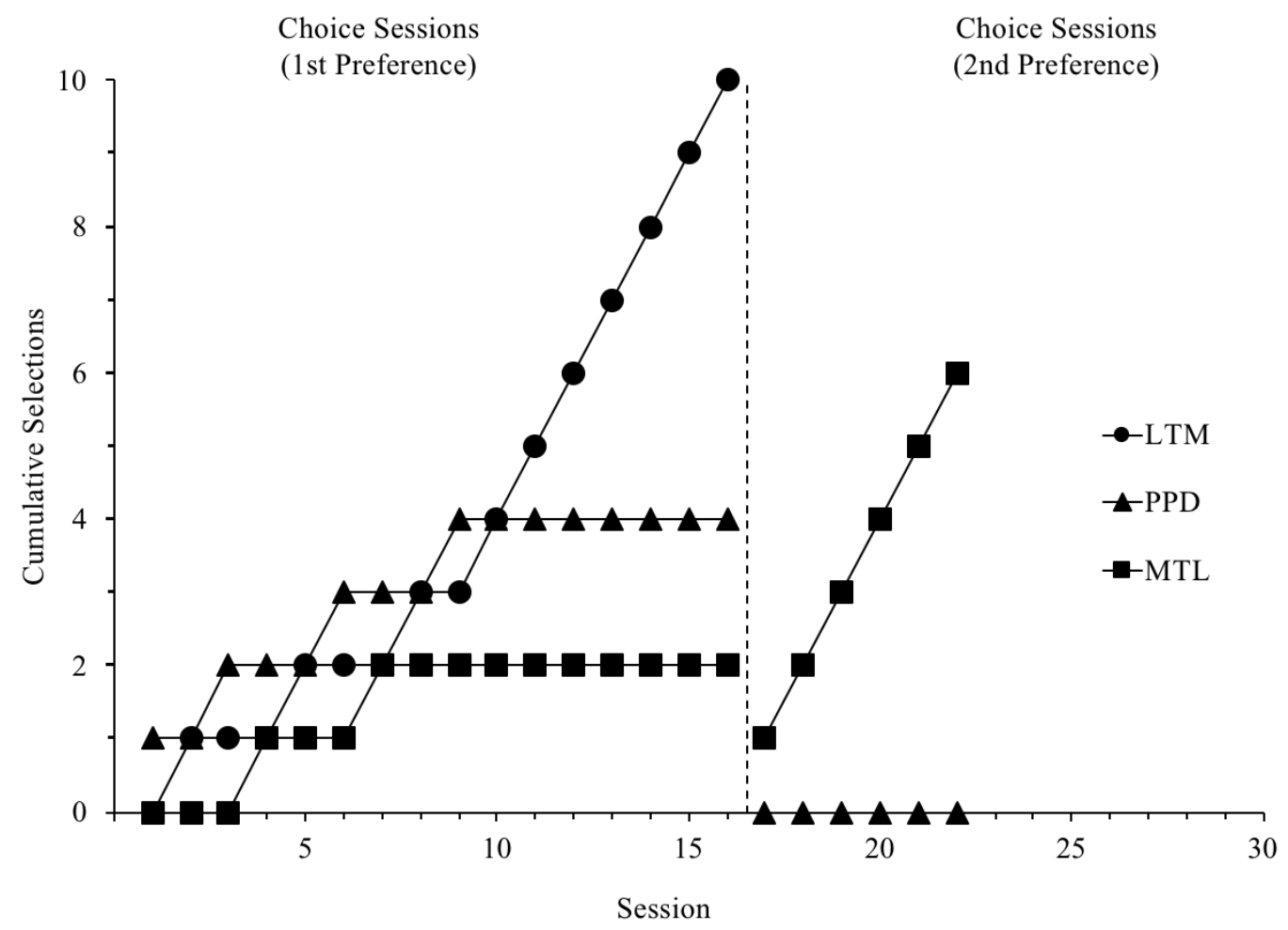

Figure 5. Cumulative treatment selections for Mrs. Roberts during choice sessions. 


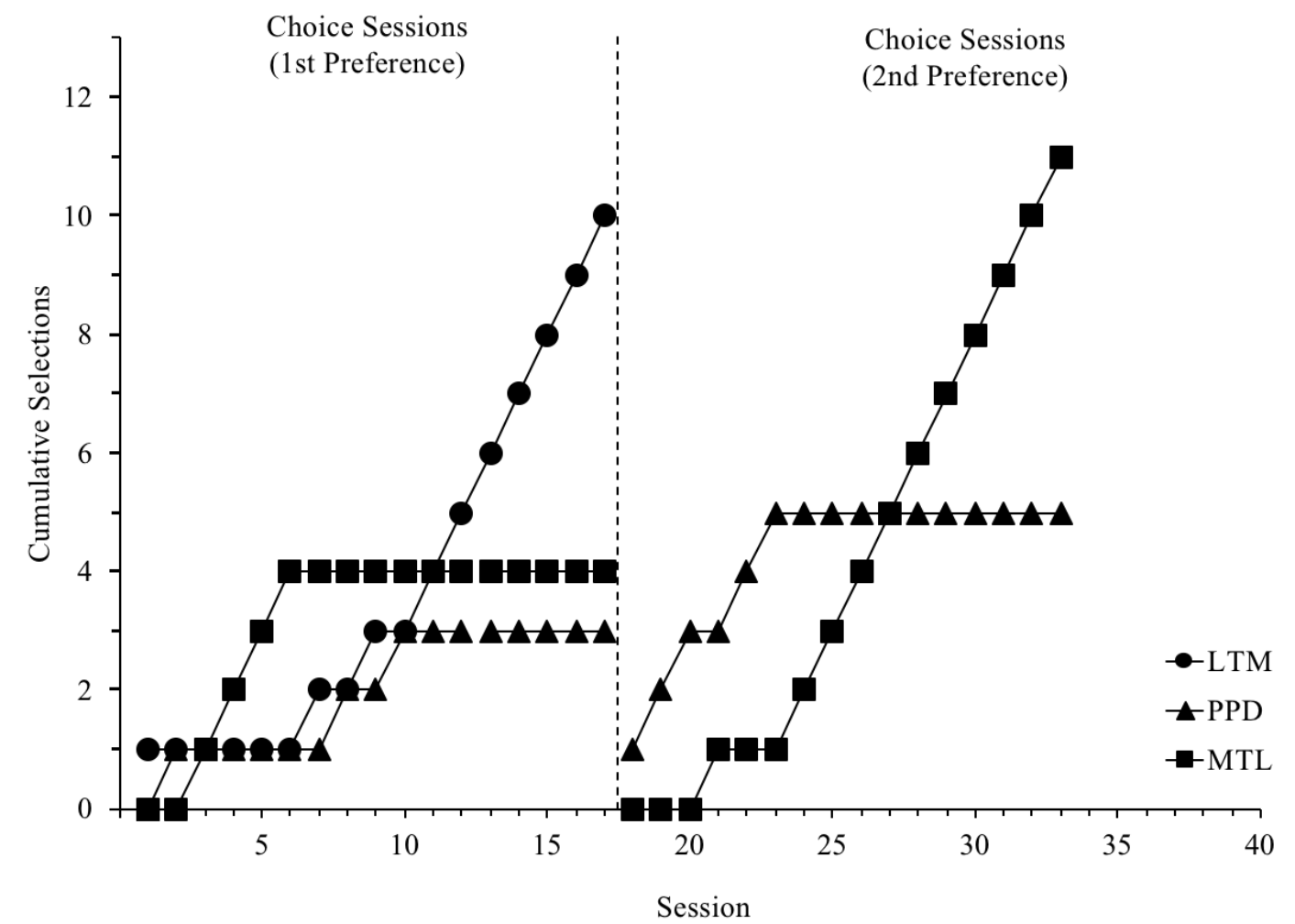

Figure 6. Cumulative treatment selections for Mr. Roberts during choice sessions. 


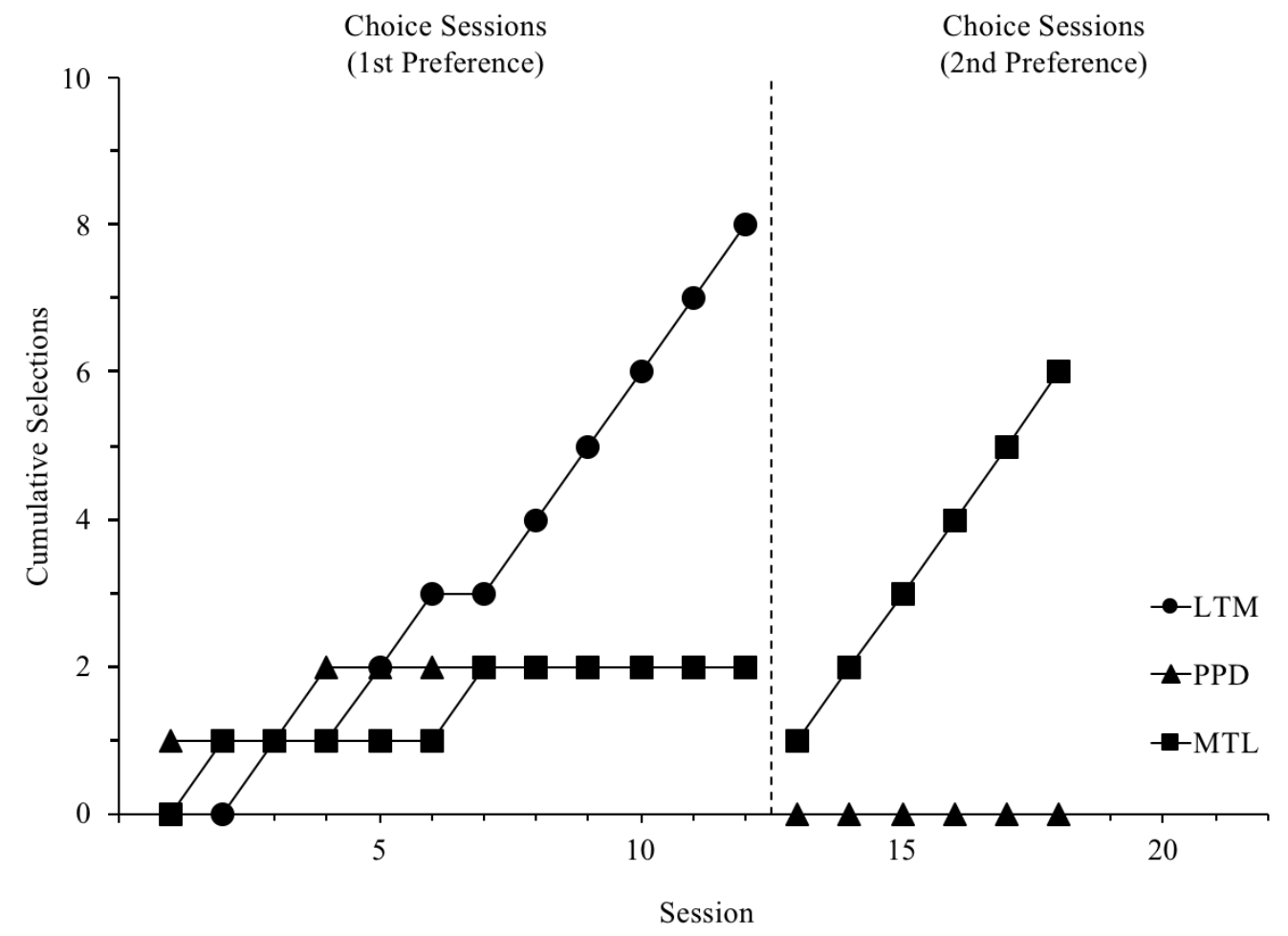

Figure 7. Cumulative treatment selections for Mrs. Davis during choice sessions. 


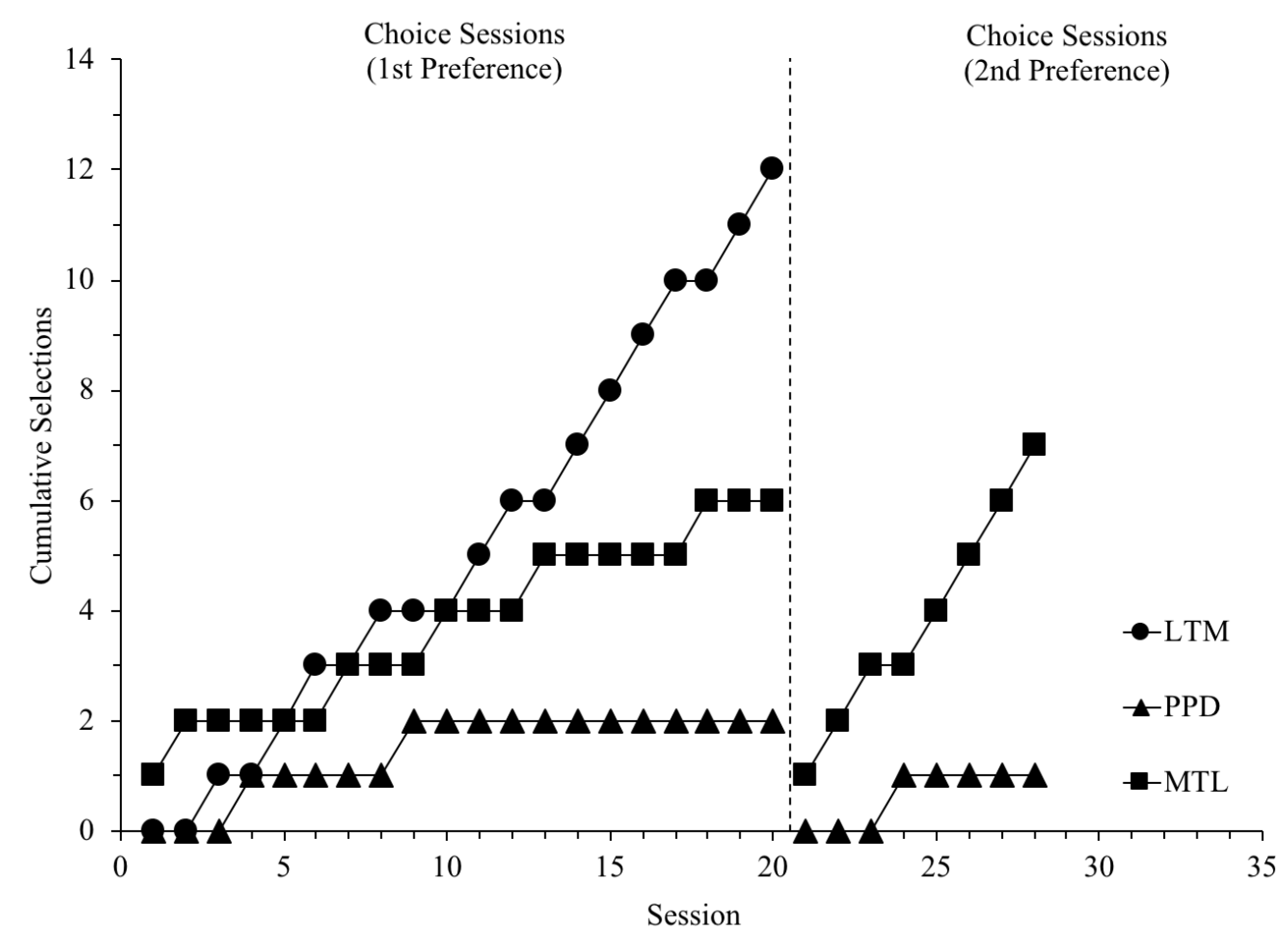

Figure 8. Cumulative treatment selections for Mr. Sullivan during choice sessions. 
TEI-SF
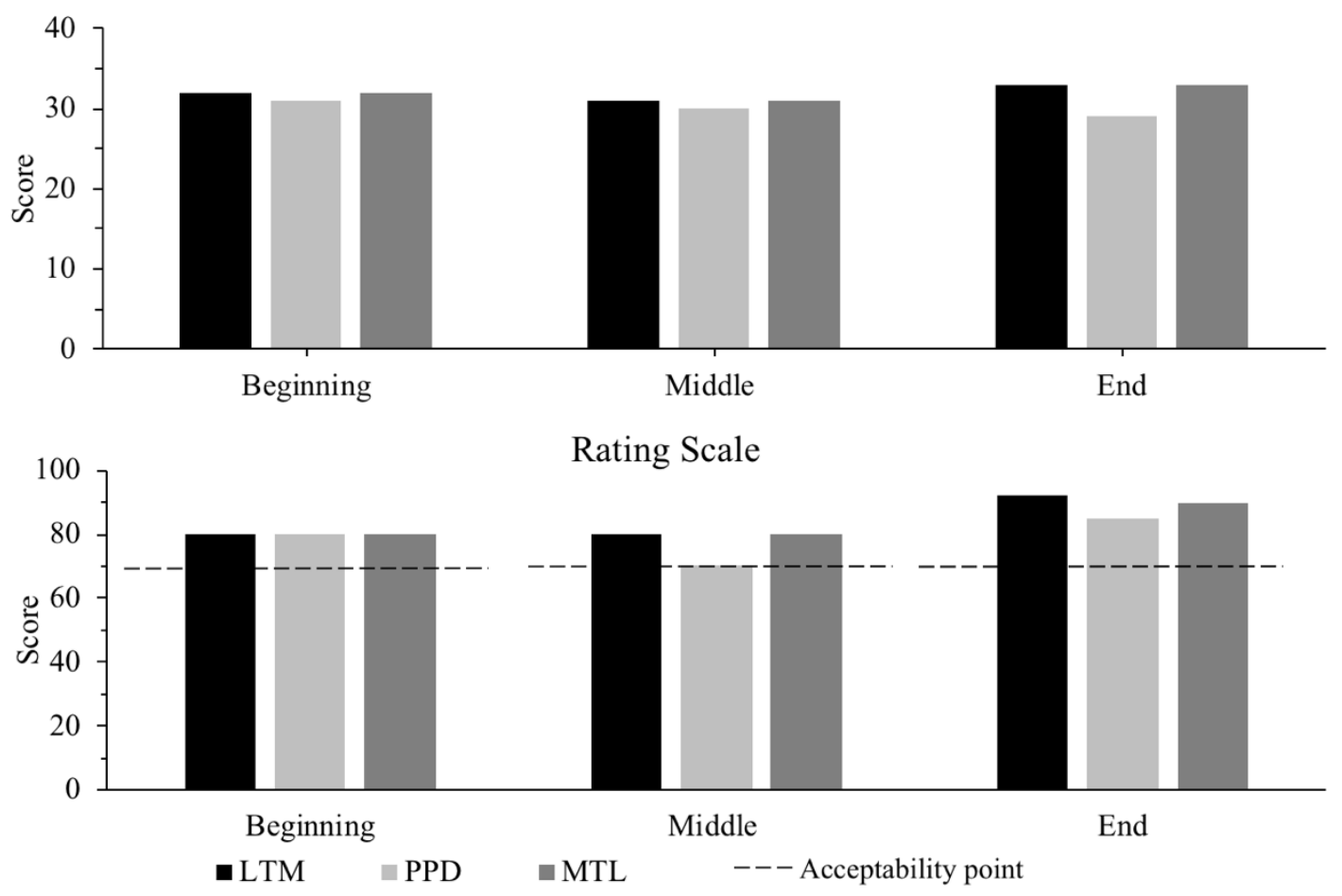

Figure 9. Treatment acceptability ratings for Mrs. Roberts. The top panel corresponds to the TEI-SF, and the bottom panel corresponds to Mrs. Robert's acceptability criterion rating scale. 
TEI-SF
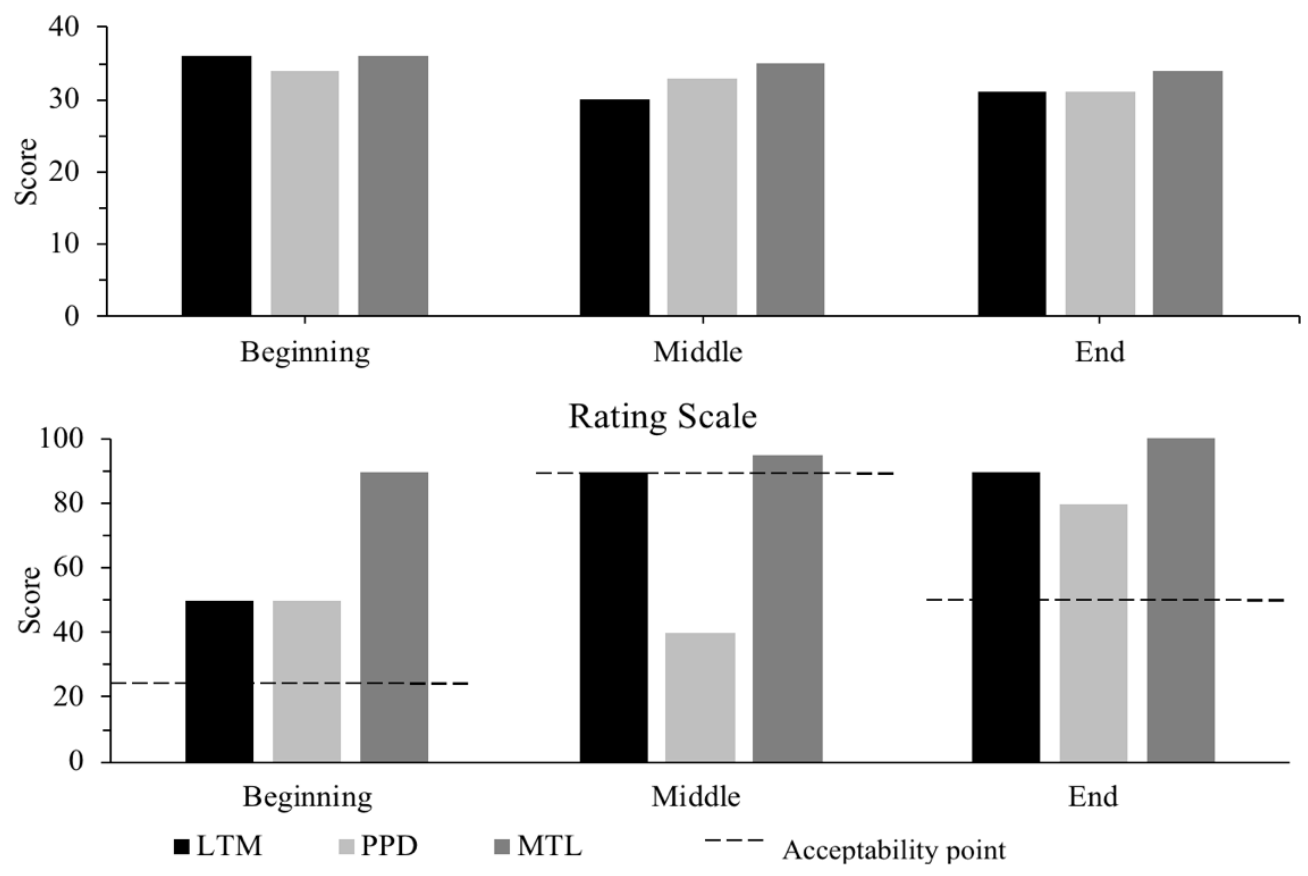

Figure 10. Treatment acceptability ratings for Mr. Roberts. The top panel corresponds to the TEI-SF and the bottom panel corresponds to the acceptability criterion rating scale. 


\section{TEI-SF}
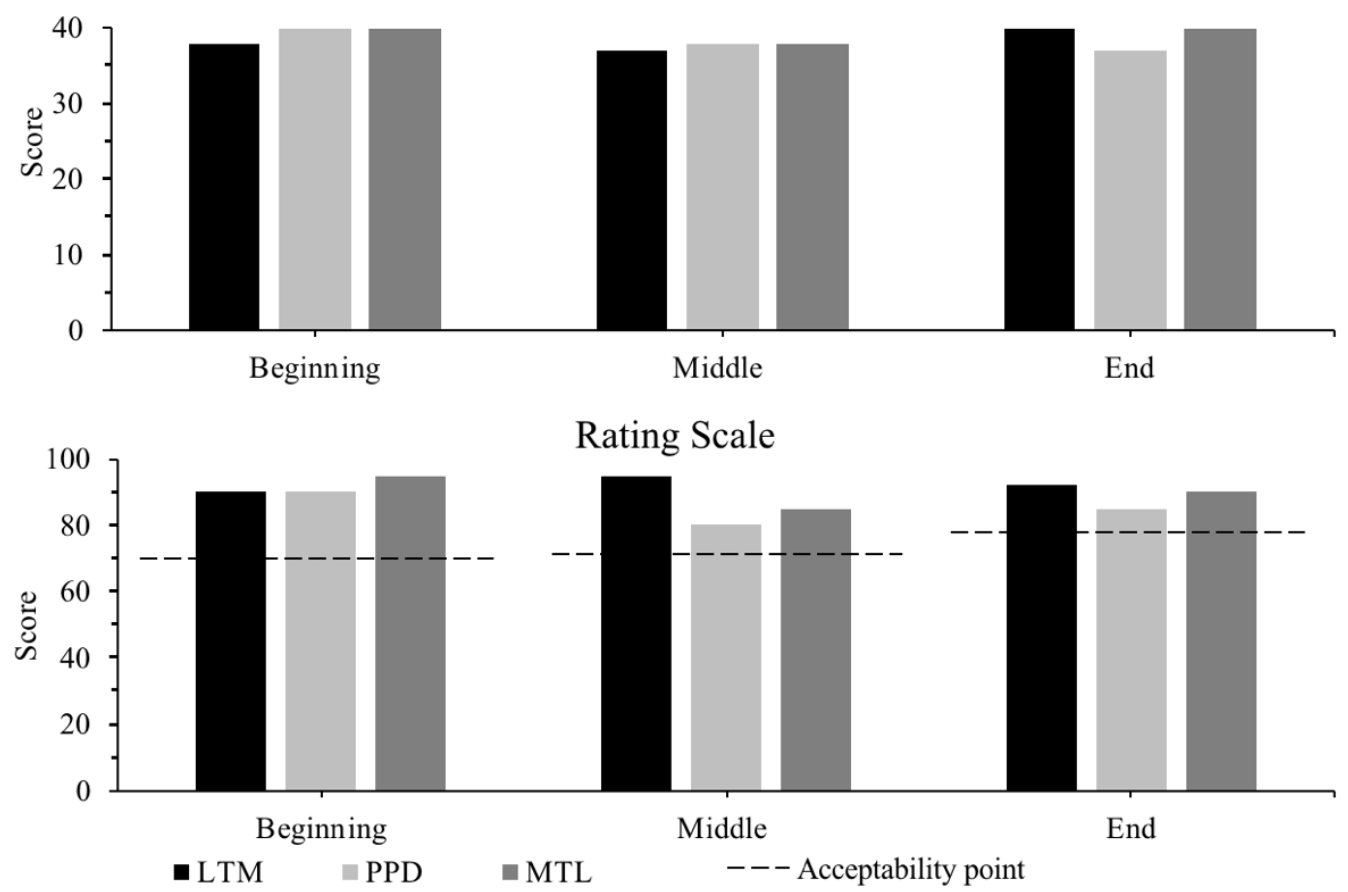

Figure 11. Treatment acceptability ratings for Mrs. Davis. The top panel corresponds to the TEI$\mathrm{SF}$ and the bottom panel corresponds to the acceptability criterion rating scale. 
TEI-SF
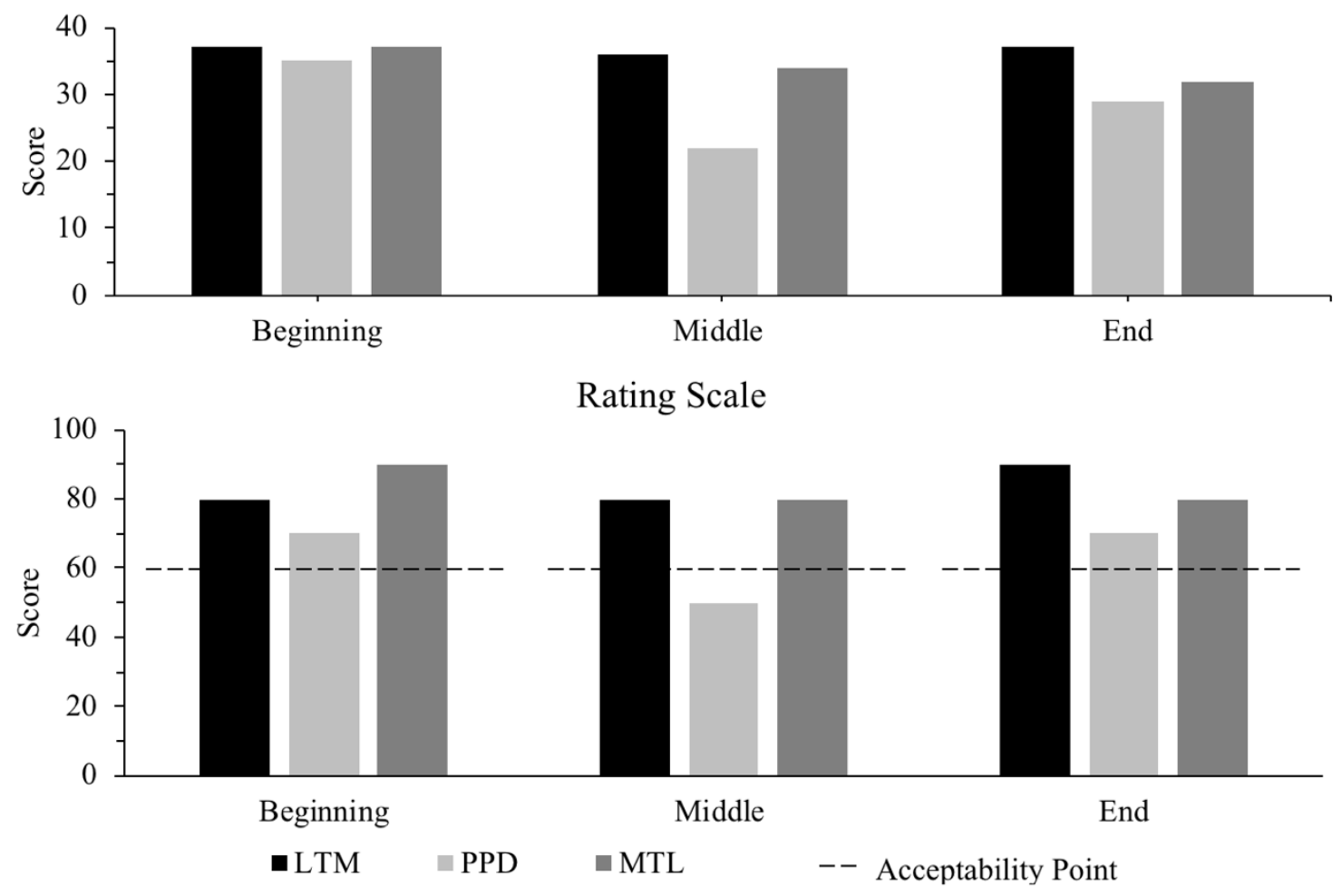

Figure 12. Treatment acceptability ratings for Mrs. Sullivan. The top panel corresponds to the TEI-SF and the bottom panel corresponds to the acceptability criterion rating scale. 


\section{References}

Cariveau, T., Kodak, T., \& Campbell, V. (2016). The effects of intertrial interval and instructional format on skill acquisition and maintenance for children with autism spectrum disorders. Journal of Applied Behavior Analysis, 49, 809-825. doi:

10.1002/jaba.322

Carr, J. E., Nicolson, A. C., \& Higbee, T. S. (2000). Evaluation of a brief multiple-stimulus preference assessment in a naturalistic context. Journal of Applied Behavior Analysis, 33, 353-357. doi:10.1901/jaba.2000.33-353

Cengher, M., Shamoun, K., Moss, P., Roll, D., Feliciano, G., \& Fienup, D. M. (2015). A Comparison of the effects of two prompt-fading strategies on skill acquisition in children with autism spectrum disorders. Behavior Analysis in Practice, 1-11. doi: $10.1007 / \mathrm{s} 40617-015-0096-6$

Cronin, K. A., \& Cuvo, A. J. (1979). Teaching mending skills to mentally retarded adolescents. Journal of Applied Behavior Analysis, 12, 401-406. doi: 10.1901/jaja/1979.12-401

Davis, C. A., Reichle, J. E., \& Southard, K. L. (2000). High-probability requests and a preferred item as a distractor: Increasing successful transitions in children with behavior problems. Education and Treatment of Children, 423-440. doi: 10.1353/etc.2013.0008

DeLeon, I. G., \& Iwata, B. A. (1996). Evaluation of a multiple-stimulus presentation format for assessing reinforcer preferences. Journal of Applied Behavior Analysis, 29, 519-532. doi: 10.1901/jaba.1996.29-519

Elliott, S. N. (1988). Acceptability of behavioral treatments: Review of variables that influence treatment selection. Professional Psychology: Research and Practice, 19, 68-80. doi: $10.1037 / 0735-7028.19 .1 .68$ 
Fentress, G. M., \& Lerman, D. C. (2012). A comparison of two prompting procedures for teaching basic skills to children with autism. Research in Autism Spectrum Disorders, 6, 1083-1090. doi: 10.1016/j.rasd.2012.02.006

Fisher, W. W., Kodak, T., \& Moore, J. W. (2007). Embedding an identity-matching tasks within a prompting hierarchy to facilitate acquisition of conditional discrimination in children with autism. Journal of Applied Behavior Analysis, 40, 489-499. doi:

10.1901/jaba.2007.40-489

Gabor, A. M., Fritz, J. N., Roath, C. T., Rothe, B. R., \& Gourley, D. A. (2016). Parent preference for reinforcement-based interventions for problem behavior maintained by positive reinforcement. Journal of Applied Behavior Analysis. 49, 215-227. doi: 10.1002/jaba.286

Giannakakos, A. R., Vladescu, J. C., Kisamore, A. N., \& Reeve, S. A. (2016). Using video modeling with voiceover instruction plus feedback to train staff to implement direct teaching procedures. Behavior Analysis in Practice, 9, 126-134. doi:10.1009/s40617-0150097-5

Grow, L. L., Carr, J. E., Kodak, T. M., Jostad, C. M., \& Kisamore, A. N. (2011). A comparison of methods for teaching receptive labeling to children with autism spectrum disorders. Journal of Applied Behavior Analysis, 44, 475-498. doi: 10.1901/jaba/2011.44-475

Hanley, G. P. (2010). Toward effective and preferred programming: A case for the objective measurement of social validity with recipients of behavior-change programs. Behavior Analysis in Practice, 3, 13-21. Retrieved from https:/www.ncbi.nlm.nih.gov/pubmed/22 479668

Herrnstein, R. J. (1964). Secondary reinforcement and rate of primary reinforcement. Journal of the Experimental Analysis of Behavior, 7, 27-36. doi:10.1901/jeab.1964.7-27 
Ingvarsson, E. T. (2011). Parent-implemented mand training: acquisition of framed manding in a young boy with partial hemispherectomy. Journal of Applied Behavior Analysis, 44, $205-$ 209. doi: 10.1901/jaba.2011.44-205

Kazdin, A. E. (1980). Acceptability of alternative treatments for deviant child behavior. Journal of Applied Behavior Analysis, 13, 259-273. doi: 10.1901/jaba.1980.13-259

Kelley, M. L., Heffer, R. W., Gresham, F. M., \& Elliott, S. N. (1989). Development of a modified treatment evaluation inventory. Journal of Psychopathology and Behavioral Assessment, 11, 235-247. doi:10.1009/BF00960495

Kodak, T., Campbell, V., Bergmann, S., LeBlanc, B., Kurtz-Nelson, E., Cariveau, T., ... \& Mahon, J. (2016). Examination of efficacious, efficient, and socially valid errorcorrection procedures to teach sight words and prepositions to children with autism spectrum disorder. Journal of Applied Behavior Analysis, 49, 532-547. doi: 10.1002/jaba. 310

Lafasakis, M., \& Sturmey, P. (2007). Training parent implementation of discrete-trial teaching: Effects on generalization of parent teaching and child correct responding. Journal of Applied Behavior Analysis, 40, 685-689. doi: 10.1901/jaba.2007.695-689

Lerman, D. C., Vorndran, C. M., Addison, L., \& Kuhn, S. C. (2004). Preparing teachers in evidence-based practices for young children with autism. School Psychology Review, 33, 510-526. Retrieved from https://eric.ed.gov/?id=EJ683753

Libby, M. E., Weiss, J. S., Bancroft, S., \& Ahearn, W. H. (2008). A comparison of most-to-least and least-to-most prompting on the acquisition of solitary play skills. Behavior Analysis in Practice, 1, 37-43. Retrieved from https://www.ncbi.nlm.nih.gov/pmc/articles/ PMC2846579/ 
Lovaas, O. I., Koegel, R., Simmons, J. Q., \& Long, J. S. (1973). Some generalization and followup measures on autistic children in behavior therapy. Journal of Applied Behavior Analysis, 6, 131-165. doi: 10.1901/jaba.1973.6-131

Luczynski, K. C., \& Hanley, G. P. (2009). Do children prefer contingencies? An evaluation of the efficacy of and preference for contingent versus noncontingent social reinforcement during play. Journal of Applied Behavior Analysis, 42, 511-525.

doi:10.1901/jaba.2009.42-511

MacDuff, G. S., Krantz, P. J., \& McClannahan, L. E. (2001). Prompts and prompt-fading strategies for people with autism. Making a difference: Behavioral intervention for autism, 37-50.

McKay, J. A., Weiss, J. S., Dickson, C. A., \& Ahearn, W. H. (2014). Comparison of prompting hierarchies on the acquisition of leisure and vocational skills. Behavior Analysis in Practice, 7, 91. doi: 10.1007/s40617-014-0022-3

Miles, N. I., \& Wilder, D. A. (2009). The effects of behavioral skills training on parent implementation of guided compliance. Journal of Applied Behavior Analysis, 42, 405410. doi: 10.1901/jaba.2009.42-405

Miltenberger, R. G. (1990). Assessment of treatment acceptability: A review of the literature. Topics in Early Childhood Special Education, 10, 24-38. doi: 10.1177/02711 2149001000304

Najdowski, A. C., Wallace, M. D., Penrod, B., Tarbox, J., Reagon, K., \& Higbee, T. S. (2008). Parent-conducted experimental functional analyses of inappropriate mealtime behavior. Journal of Applied Behavior Analysis, 41, 459-465. doi: 10.1901/jaba.2008.41-459 
Reimers, T. M., \& Wacker, D. P. (1992). Acceptability of behavioral treatments for children: Analog and naturalistic evaluations by parents. School Psychology Review, 21, 628-644. http://web.b.ebscohost.com/ehost/detail/detail?vid=1\&sid=20e16958-0880-4f55-bf45aacdfb090628\%40sessionmgr103\&bdata=JkF1dGhUeXB1PWlwLHVpZCZzaXRIPWVo b3N0LWxpdmUmc2NvcGU9c210ZQ\%3d\%3d\#AN=9604173913\&db=aph

Reimers, T., Wacker, D., \& Koeppl, G. (1987). Acceptability of behavioral interventions: A review of the literature. School Psychology Review, 16, 212-227. Retrieved from http://www.nasponline.org/publications/periodicals/spr/volume-16/volume-16-issue2/acceptability-of-behavioral-interventions-a-review-of-the-literature

Schuster, J. W., Gast, D. L., Wolery, M., \& Guiltinan, S. (1988). The effectiveness of a constant time-delay procedure to teach chained responses to adolescents with mental retardation. Journal of Applied Behavior Analysis, 21, 169-178. doi: 10.1901/jaba.1988.21-169

Seaver, J. L., \& Bourret, J. C. (2014). An evaluation of response prompts for teaching behavior chains. Journal of Applied Behavior Analysis, 47, 777-792. doi: 10.1002/jaba.159

Severtson, J. M., \& Carr, J. E. (2012). Training novice instructors to implement errorless discrete-trial teaching: A sequential analysis. Behavior Analysis in Practice, 5, 13-23. Retrieved from https://www.ncbi.nlm.nih.gov/pmc/articles/PMC3592485/pdf/i19981929-5-2-13.pdf

Slocum, S. K., \& Tiger, J. H. (2011). An assessment of the efficiency of and child preference for forward and backward chaining. Journal of Applied Behavior Analysis, 44, 793-805. doi: 10.1901/jaba.2011.44-793 
Striefel, S., \& Wetherby, B. (1973). Instruction-following behavior of a retarded child and its controlling stimuli. Journal of Applied Behavior Analysis, 6, 663-670. doi: 10.1901/jaba.1973.6-663

Touchette, P. E. (1971). Transfer of stimulus control: Measuring the moment of transfer. Journal of the Experimental Analysis of Behavior, 15, 347-354. doi: 10.1901/jeab.1971.15-347

Walker, G. (2008). Constant and progressive time delay procedures for teaching children with autism: A literature review. Journal of Autism and Developmental Disorders, 38, 261275. doi: 10.1007/s10803-007-0390-4 
Appendix A.

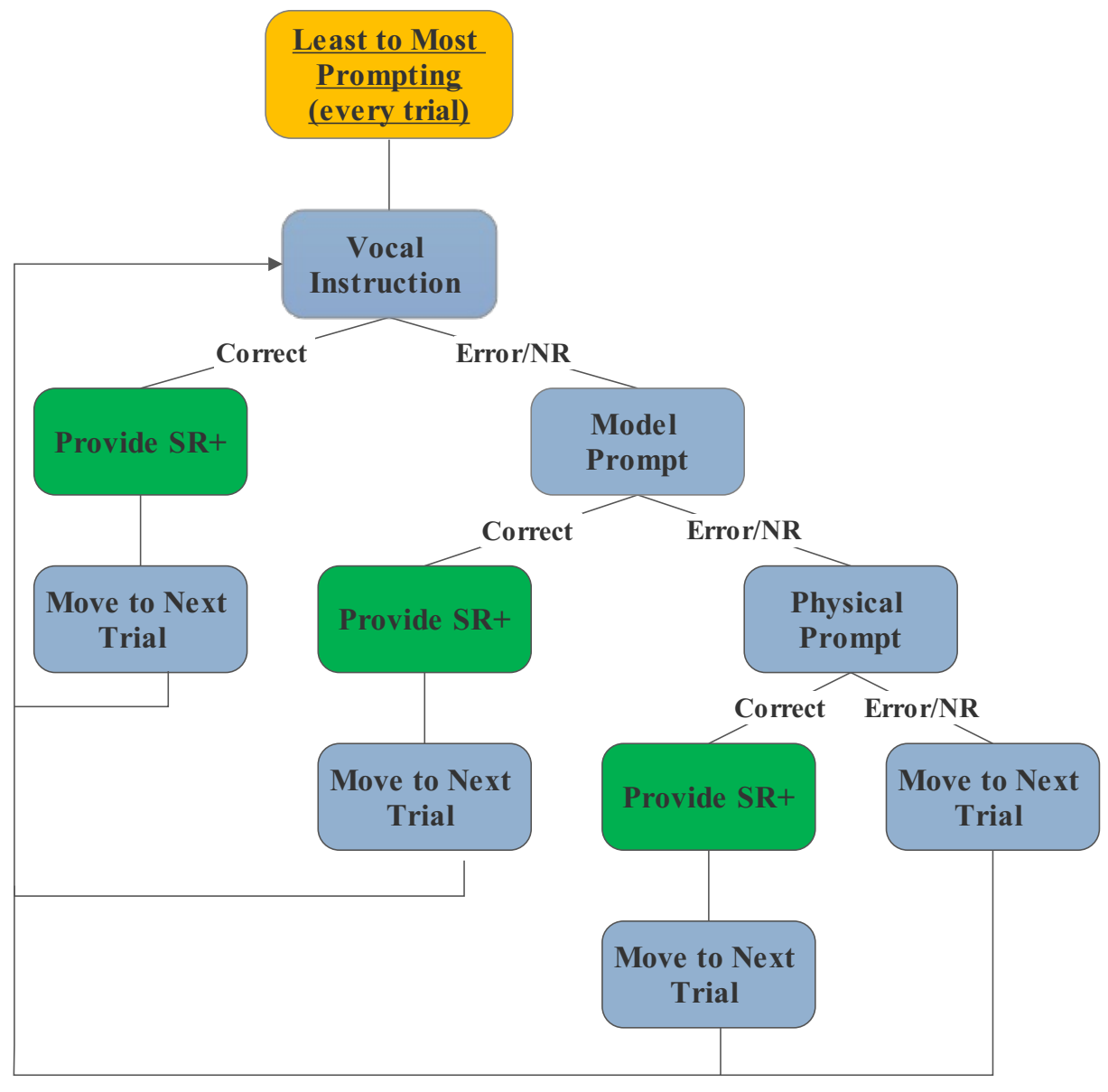


Appendix B.

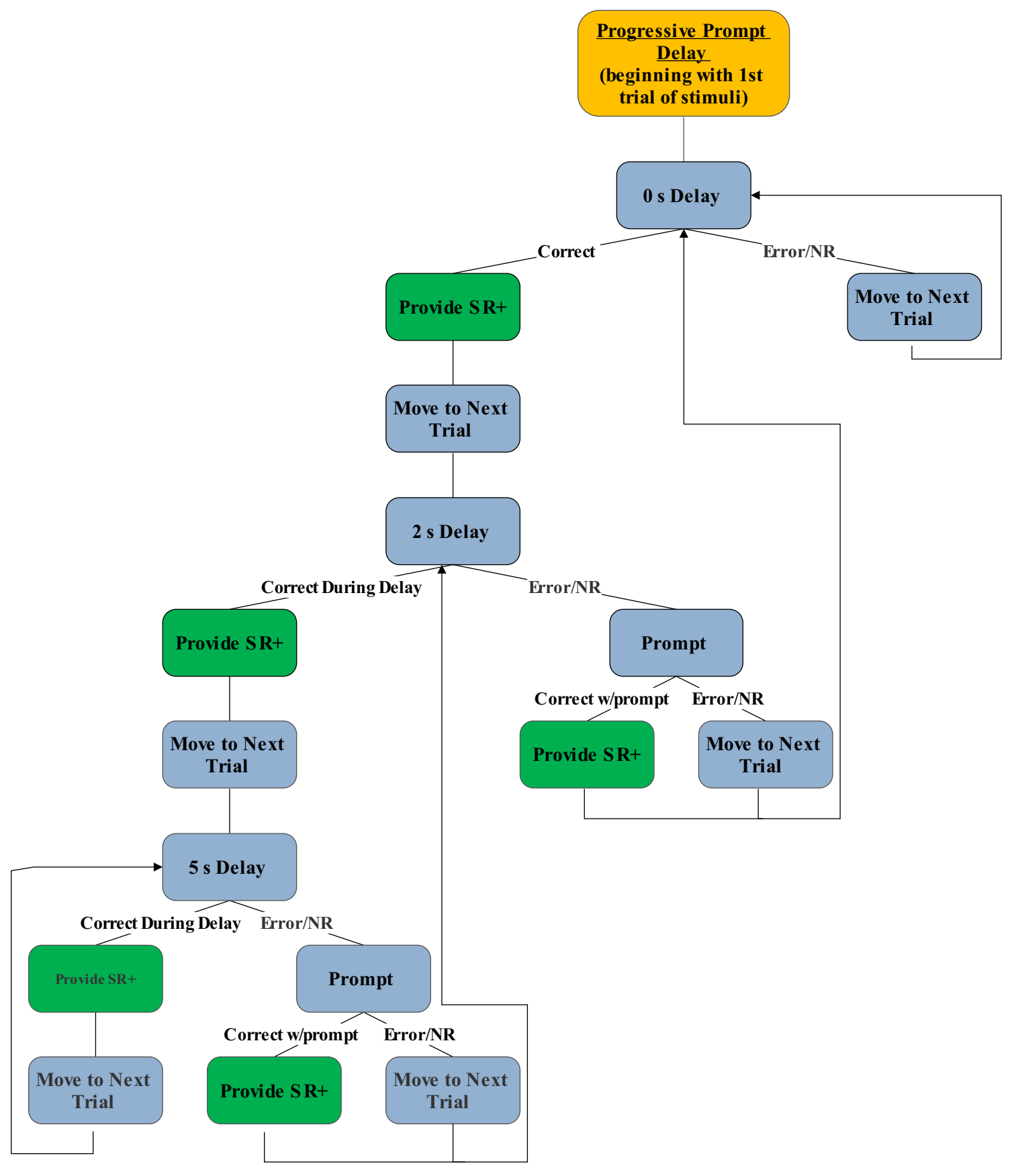


Appendix C.

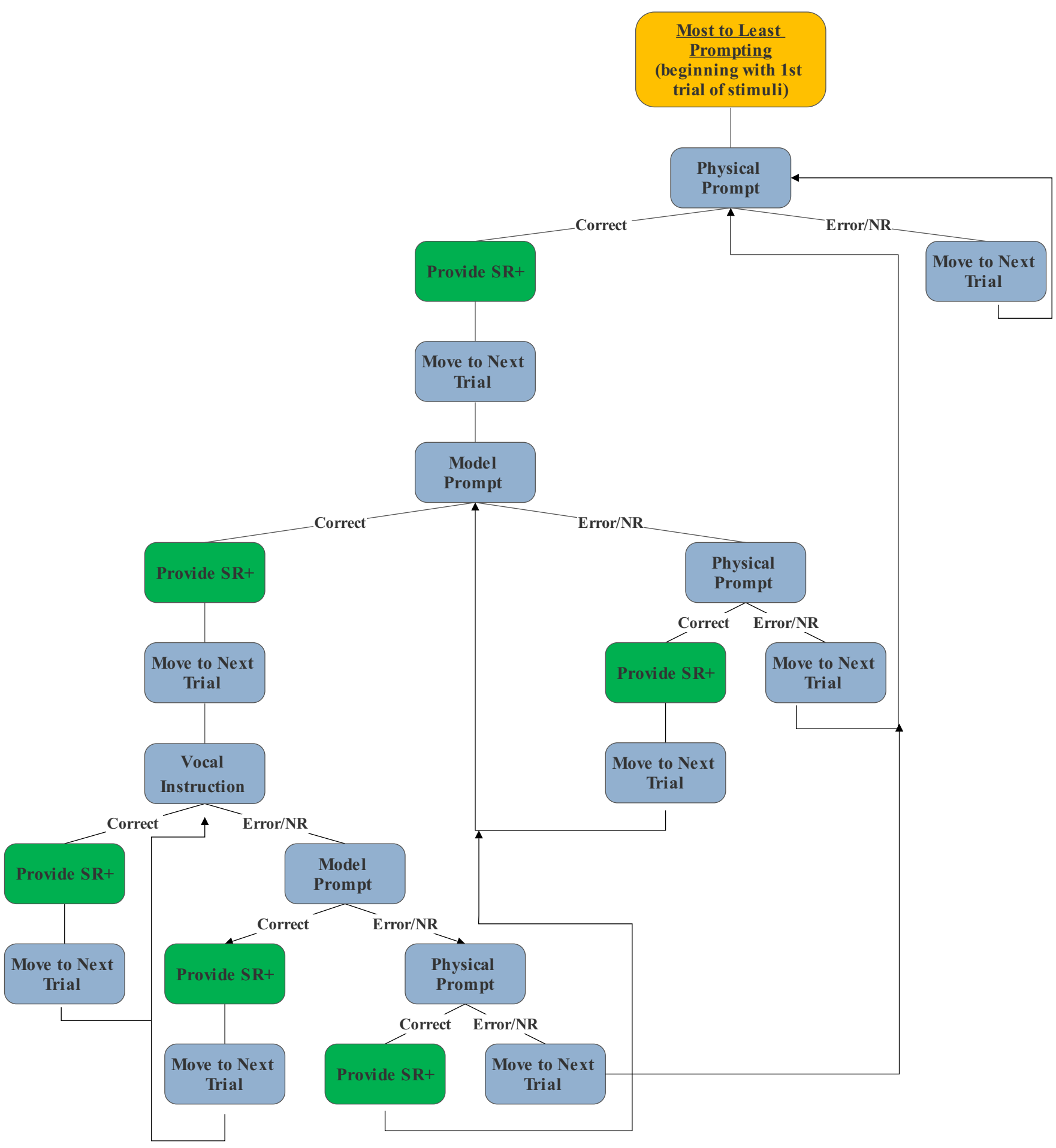


Appendix D.

\section{Sequence of Study Training Procedures}

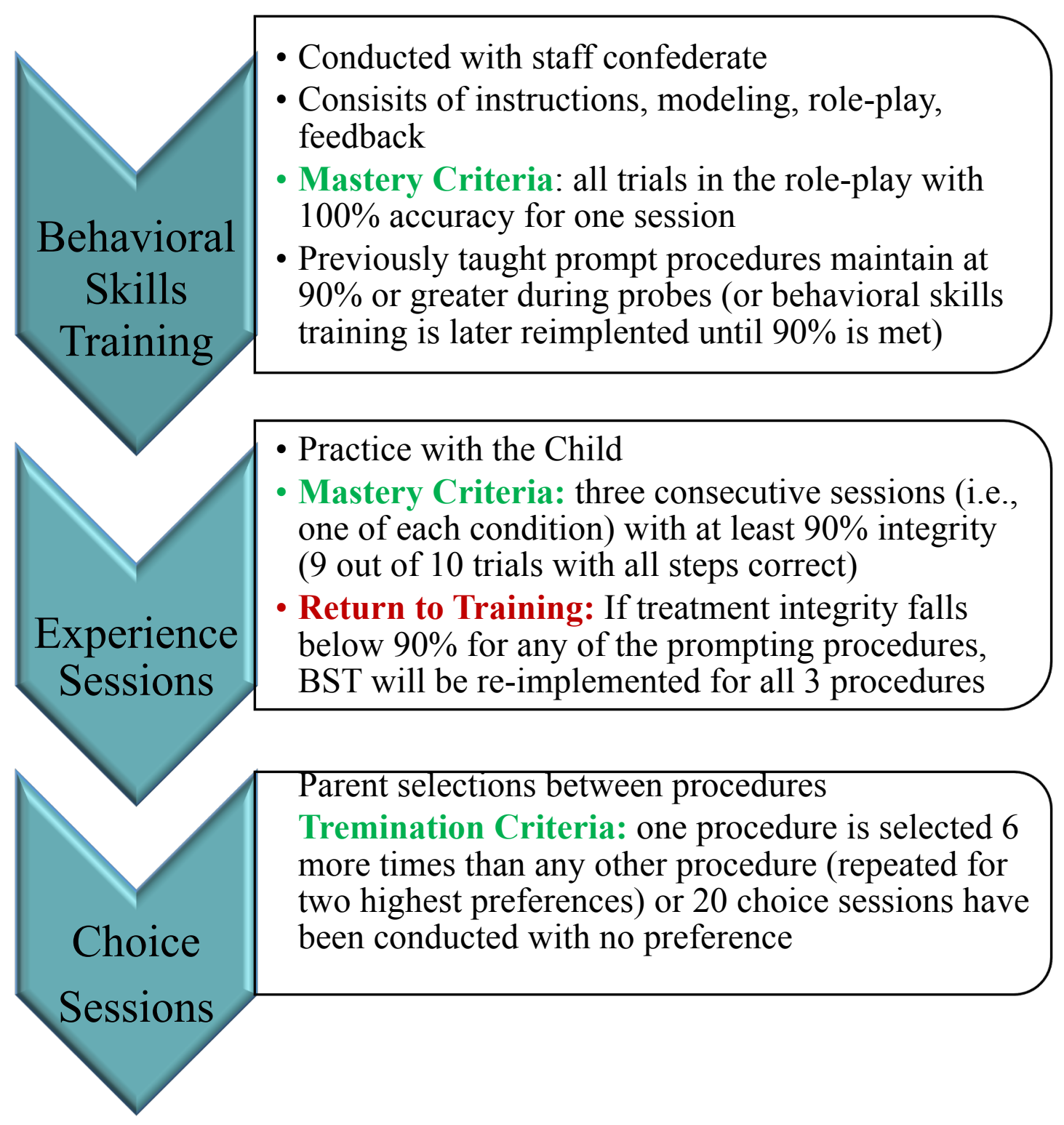


Appendix E.

Example of Parent Instruction Cards

\section{During all Sessions}

- Get the child's attention before you give an instruction

- Provide reinforcers for correct answers (e.g., praise and iPad for $30 \mathrm{~s}$ )

- Present the target card and 2 other cards on the table

- Randomly vary the order of cards on each trial (middle, left, right)

- Problem Behavior:

- Ignore and keep neutral facial expression when problem behavior occurs

- Move to next prompt level immediately

\section{Most-to-Least (Do, Show, Tell)}

Gradually reduce assistance from guiding your child to providing an instruction only. Begin the first trial with a do prompt (use hand-over-hand guidance to have him touch the correct card while giving the instruction)

Following a correct response, move to a show prompt (point to the correct answer while providing the instruction) on next trial

- If correct, start next trial with tell prompt (provide instruction)

- If incorrect, use the do prompt

If the child does not get the correct response with the first prompt used for a trial, the instruction should be repeated and a prompt one level higher should be provided until you reach the do prompt or a correct prompted response occurs

- Begin each trial with one prompt level less intrusive than the prompt used to get a correct response.

Continue this progression for the 10-trial session
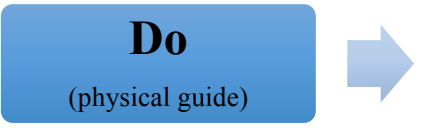

\section{Show}




\section{During all Sessions}

- Get the child's attention before you give an instruction

- Provide reinforcers for correct answers (e.g., praise and iPad for $30 \mathrm{~s}$ )

- Present the target card and 2 other cards on the table

- Randomly vary the order of cards on each trial (middle, left, right)

- Problem Behavior:

- Ignore and keep neutral facial expression when problem behavior occurs

○ Move to next prompt level immediately

\section{Least-to-Most (Tell, Show, Do)}

Add prompts as necessary to help a child perform the skill

Start each trial with a tell prompt (provide the instruction)

If the child does not engage in correct response within $5 \mathrm{sec}$, use a show prompt (point to the correct answer while providing the instruction)

- If correct, start next trial with tell prompt

- If incorrect, use a do prompt (use hand-over-hand guidance to have him touch the card while giving the instruction)

Continue this progression for the 10-trial session
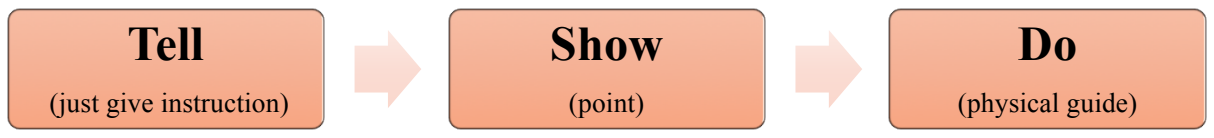


\section{During all Sessions}

- Get the child's attention before you give an instruction

- Provide reinforcers for correct answers (e.g., praise and iPad for $30 \mathrm{~s}$ )

- Present the target card and 2 other cards on the table

- Randomly vary the order of cards on each trial (middle, left, right)

- Problem Behavior:

- Ignore and keep neutral facial expression when problem behavior occurs

- Move to next prompt level immediately

\section{Prompt Delay (0 sec, 2 sec, 5 sec)}

Start training with no delay $(0 \mathrm{sec})$ between the instruction and a prompt, and increase the time the child has until the prompt

Begin the first trial with an immediate prompt (simultaneous instruction and prompt)

Following a correct response, move to a 2 -sec delay (provide instruction, but wait $2 \mathrm{sec}$ before giving prompt and repeating the instruction) on next trial

- If correct during delay, start next trial with a 5-sec delay to the prompt

- If incorrect during delay, start next trial with an immediate $(0-\mathrm{sec})$ prompt

- Child needs to respond independently and correctly during the delay to progress to a longer delay

Continue this progression for the 10 -trial session

\section{0 sec}

\section{$2 \mathrm{sec}$}

\section{$5 \mathrm{sec}$}


Appendix F.

\begin{tabular}{|c|c|c|c|}
\hline \multicolumn{4}{|c|}{ Least-to-Most } \\
\hline Trial & Script 1 & Script 2 & Script 3 \\
\hline 1 & $\begin{array}{l}\text { Attend } \\
\text { No response to Vocal } \\
\text { Respond to Model } \\
\text { No PB }\end{array}$ & $\begin{array}{l}\text { Attend } \\
\text { Respond to Vocal } \\
\text { No PB }\end{array}$ & $\begin{array}{l}\text { Attend } \\
\text { Error to Vocal } \\
\text { Error to Model } \\
\text { Respond to Physical } \\
\text { No PB }\end{array}$ \\
\hline 2 & $\begin{array}{l}\text { Attend } \\
\text { Respond to Vocal } \\
\text { No PB }\end{array}$ & $\begin{array}{l}\text { No attending } \\
\text { Error to Vocal } \\
\text { No Response to Model } \\
\text { Respond to Physical } \\
\text { No PB }\end{array}$ & $\begin{array}{l}\text { Attend } \\
\text { No Response on Vocal } \\
\text { Respond to Model } \\
\text { No PB }\end{array}$ \\
\hline 3 & $\begin{array}{l}\text { Attend } \\
\text { No response to Vocal } \\
\text { Error on Model } \\
\text { Respond to Physical } \\
\text { No PB }\end{array}$ & $\begin{array}{l}\text { Attend } \\
\text { No Response on vocal } \\
\text { Respond to Model } \\
\text { No PB }\end{array}$ & $\begin{array}{l}\text { Attend } \\
\text { No Response on Vocal } \\
\text { Engage in PB } \\
\text { Respond to Model } \\
\text { No PB }\end{array}$ \\
\hline 4 & $\begin{array}{l}\text { Attend } \\
\text { Respond to Vocal } \\
\text { No PB }\end{array}$ & $\begin{array}{l}\text { Attend } \\
\text { Respond to Vocal } \\
\text { No PB }\end{array}$ & $\begin{array}{l}\text { No attending } \\
\text { Error on Vocal } \\
\text { No response on Model } \\
\text { Respond to Physical } \\
\text { No PB } \\
\end{array}$ \\
\hline 5 & $\begin{array}{l}\text { Attend } \\
\text { Error on Vocal } \\
\text { Engage in PB } \\
\text { Respond to Model }\end{array}$ & $\begin{array}{l}\text { Attend } \\
\text { Error to Vocal } \\
\text { No Response to Model } \\
\text { Respond to Physical } \\
\text { No PB }\end{array}$ & $\begin{array}{l}\text { Attend } \\
\text { Error to Vocal } \\
\text { No Response to Model } \\
\text { Respond to Physical } \\
\text { No PB }\end{array}$ \\
\hline 6 & $\begin{array}{l}\text { Attend } \\
\text { Error on Vocal } \\
\text { No Response to Model } \\
\text { Respond to Physical } \\
\text { No PB }\end{array}$ & $\begin{array}{l}\text { Attend } \\
\text { Error on Vocal } \\
\text { Respond to Model } \\
\text { No PB }\end{array}$ & $\begin{array}{l}\text { Attend } \\
\text { Respond to Vocal } \\
\text { No PB }\end{array}$ \\
\hline 7 & $\begin{array}{l}\text { No attending } \\
\text { Respond to Vocal } \\
\text { No PB }\end{array}$ & $\begin{array}{l}\text { Attend } \\
\text { Error to vocal } \\
\text { Error to model } \\
\text { Respond to Physical } \\
\text { No PB }\end{array}$ & $\begin{array}{l}\text { Attend } \\
\text { Respond to Vocal } \\
\text { No PB }\end{array}$ \\
\hline 8 & $\begin{array}{l}\text { Attend } \\
\text { Respond to Vocal } \\
\text { No PB }\end{array}$ & $\begin{array}{l}\text { Attend } \\
\text { No Response to Vocal } \\
\text { No Response to Model } \\
\text { Engage in PB } \\
\text { Resist Physical }\end{array}$ & $\begin{array}{l}\text { Attend } \\
\text { No Response to Vocal } \\
\text { Respond to Model } \\
\text { No PB }\end{array}$ \\
\hline 9 & $\begin{array}{l}\text { Attend } \\
\text { No response to Vocal } \\
\text { Engage in PB } \\
\text { Error on Model } \\
\text { Respond to Physical }\end{array}$ & $\begin{array}{l}\text { Attend } \\
\text { Respond to Vocal } \\
\text { No PB }\end{array}$ & $\begin{array}{l}\text { Attend } \\
\text { Error to Vocal } \\
\text { Respond to Model } \\
\text { No PB }\end{array}$ \\
\hline 10 & $\begin{array}{l}\text { Attend } \\
\text { No Response on Vocal } \\
\text { Respond to Model } \\
\text { No PB }\end{array}$ & $\begin{array}{l}\text { No attending } \\
\text { Error on Vocal } \\
\text { Respond to Model } \\
\text { No PB }\end{array}$ & $\begin{array}{l}\text { Attend } \\
\text { Respond to Vocal } \\
\text { No PB }\end{array}$ \\
\hline $\begin{array}{l}\text { Over- } \\
\text { view }\end{array}$ & $\begin{array}{l}\text { 4 Vocal } \\
3 \text { Model } \\
3 \text { Physical } \\
\end{array}$ & $\begin{array}{l}\text { 3 Vocal } \\
3 \text { Model } \\
4 \text { Physical } \\
\end{array}$ & $\begin{array}{l}3 \text { Vocal } \\
4 \text { Model } \\
3 \text { Physical }\end{array}$ \\
\hline
\end{tabular}




\begin{tabular}{|c|c|c|c|}
\hline \multicolumn{4}{|c|}{ Progressive Prompt Delay } \\
\hline Trial & Script 1 & Script 2 & Script 3 \\
\hline & Begin with: 0 s & Begin with: 2 s & Begin with: $5 \mathbf{s}$ \\
\hline 1 & $\begin{array}{l}\text { Attend } \\
\text { Respond to 0s } \\
\text { No PB }\end{array}$ & $\begin{array}{l}\text { Attend } \\
\text { No response during } 2 \mathrm{~s} \\
\text { Respond to prompt } \\
\text { No PB }\end{array}$ & $\begin{array}{l}\text { Attend } \\
\text { Respond during } 5 \mathrm{~s} \\
\text { No PB }\end{array}$ \\
\hline 2 & $\begin{array}{l}\text { Attend } \\
\text { Engage in PB } \\
\text { No Response during } 2 \mathrm{~s} \\
\text { Respond to prompt }\end{array}$ & $\begin{array}{l}\text { Attend } \\
\text { Respond to } 0 \mathrm{~s} \\
\text { No PB }\end{array}$ & $\begin{array}{l}\text { Attend } \\
\text { Error during } 5 \mathrm{~s} \\
\text { Respond to prompt }\end{array}$ \\
\hline 3 & $\begin{array}{l}\text { Attend } \\
\text { Respond to 0s } \\
\text { No PB }\end{array}$ & $\begin{array}{l}\text { No attending } \\
\text { Error during } 2 \mathrm{~s} \\
\text { Respond to prompt } \\
\text { No PB }\end{array}$ & $\begin{array}{l}\text { Attend } \\
\text { No response during } 2 \mathrm{~s} \\
\text { Engage in PB } \\
\text { Respond to prompt }\end{array}$ \\
\hline 4 & $\begin{array}{l}\text { Attend } \\
\text { Respond during } 2 \mathrm{~s} \\
\text { No PB }\end{array}$ & $\begin{array}{l}\text { Attend } \\
\text { Respond to 0s } \\
\text { No PB }\end{array}$ & $\begin{array}{l}\text { Attend } \\
\text { Respond to } 0 \mathrm{~s} \\
\text { No PB }\end{array}$ \\
\hline 5 & $\begin{array}{l}\text { Attend } \\
\text { Respond during } 5 \mathrm{~s} \\
\text { No PB }\end{array}$ & $\begin{array}{l}\text { Attend } \\
\text { Respond during } 2 \mathrm{~s} \\
\text { No PB }\end{array}$ & $\begin{array}{l}\text { No attending } \\
\text { Error during } 2 \mathrm{~s} \\
\text { Respond to prompt } \\
\text { No PB }\end{array}$ \\
\hline 6 & $\begin{array}{l}\text { No attending } \\
\text { Respond during } 5 \mathrm{~s} \\
\text { No PB }\end{array}$ & $\begin{array}{l}\text { Attend } \\
\text { Respond during } 5 \mathrm{~s} \\
\text { No PB }\end{array}$ & $\begin{array}{l}\text { Attend } \\
\text { Error with } 0 \mathrm{~s} \\
\text { No PB } \\
\end{array}$ \\
\hline 7 & $\begin{array}{l}\text { Attend } \\
\text { Error during } 5 \mathrm{~s} \\
\text { Respond to prompt } \\
\text { No PB }\end{array}$ & $\begin{array}{l}\text { Attend } \\
\text { No response to } 5 \mathrm{~s} \\
\text { Engage in PB } \\
\text { Respond to prompt }\end{array}$ & $\begin{array}{l}\text { Attend } \\
\text { Respond to } 0 \mathrm{~s} \\
\text { No PB }\end{array}$ \\
\hline 8 & $\begin{array}{l}\text { Attend } \\
\text { No response to } 2 \mathrm{~s} \\
\text { Engage in PB } \\
\text { No response to prompt }\end{array}$ & $\begin{array}{l}\text { Attend } \\
\text { Respond during } 2 \mathrm{~s} \\
\text { No PB }\end{array}$ & $\begin{array}{l}\text { No attending } \\
\text { No response during } 2 \mathrm{~s} \\
\text { Respond to prompt } \\
\text { No PB }\end{array}$ \\
\hline 9 & $\begin{array}{l}\text { Attend } \\
\text { Respond to } 0 \mathrm{~s} \\
\text { No PB } \\
\end{array}$ & $\begin{array}{l}\text { Attend } \\
\text { Respond during } 5 \mathrm{~s} \\
\text { No PB } \\
\end{array}$ & $\begin{array}{l}\text { Attend } \\
\text { Respond to } 0 \mathrm{~s} \\
\text { No PB }\end{array}$ \\
\hline 10 & $\begin{array}{l}\text { Attend } \\
\text { Respond to } 2 \mathrm{~s} \\
\text { No PB }\end{array}$ & $\begin{array}{l}\text { Attend } \\
\text { Respond during } 5 \mathrm{~s} \\
\text { No PB }\end{array}$ & $\begin{array}{l}\text { Attend } \\
\text { Respond to } 2 \mathrm{~s} \\
\text { No PB } \\
\end{array}$ \\
\hline $\begin{array}{l}\text { Over- } \\
\text { view }\end{array}$ & $\begin{array}{l}3-0 s \\
4-2 s \\
3-5 s \\
\end{array}$ & $\begin{array}{l}2-0 s \\
4-2 s \\
4-5 s \\
\end{array}$ & $\begin{array}{l}4-0 s \\
4-2 s \\
2-5 s \\
\end{array}$ \\
\hline
\end{tabular}




\begin{tabular}{|c|c|c|c|}
\hline \multicolumn{4}{|c|}{ Most-to-Least } \\
\hline Trial & Script 1 & Script 2 & Script 3 \\
\hline & Begin with: Physical & Begin with: Vocal & Begin with: Model \\
\hline 1 & $\begin{array}{l}\text { Attend } \\
\text { Respond to Physical } \\
\text { No PB }\end{array}$ & $\begin{array}{l}\text { Attend } \\
\text { Error with Vocal } \\
\text { Respond to Model } \\
\text { No PB }\end{array}$ & $\begin{array}{l}\text { Attend } \\
\text { Error to Model } \\
\text { Respond to Physical } \\
\text { No PB }\end{array}$ \\
\hline 2 & $\begin{array}{l}\text { Attend } \\
\text { Error with Model } \\
\text { Respond to Physical } \\
\text { No PB }\end{array}$ & $\begin{array}{l}\text { No attending } \\
\text { Respond to Vocal } \\
\text { No PB }\end{array}$ & $\begin{array}{l}\text { Attend } \\
\text { No Response to Model } \\
\text { Respond to Physical } \\
\text { No PB }\end{array}$ \\
\hline 3 & $\begin{array}{l}\text { Attend } \\
\text { Respond to Model } \\
\text { No PB }\end{array}$ & $\begin{array}{l}\text { Attend } \\
\text { No Response with Vocal } \\
\text { Engage in PB } \\
\text { Respond to Model }\end{array}$ & $\begin{array}{l}\text { Attend } \\
\text { Respond to Model } \\
\text { No PB }\end{array}$ \\
\hline 4 & $\begin{array}{l}\text { Attend } \\
\text { Respond to Vocal } \\
\text { No PB }\end{array}$ & $\begin{array}{l}\text { No attending } \\
\text { Error with Vocal } \\
\text { Error with Model } \\
\text { Respond to Physical } \\
\text { No PB }\end{array}$ & $\begin{array}{l}\text { Attend } \\
\text { Respond to Vocal } \\
\text { No PB }\end{array}$ \\
\hline 5 & $\begin{array}{l}\text { Attend } \\
\text { Respond to Vocal } \\
\text { No PB }\end{array}$ & $\begin{array}{l}\text { Engage in PB } \\
\text { Attend } \\
\text { NR model } \\
\text { Resist Physical }\end{array}$ & $\begin{array}{l}\text { Attend } \\
\text { No Response with Vocal } \\
\text { Engage in PB } \\
\text { Respond to Model }\end{array}$ \\
\hline 6 & $\begin{array}{l}\text { No attending } \\
\text { No Response to Vocal } \\
\text { Error with Model } \\
\text { Respond to Physical } \\
\text { No PB }\end{array}$ & $\begin{array}{l}\text { Attend } \\
\text { Respond to Physical } \\
\text { No PB }\end{array}$ & $\begin{array}{l}\text { Attend } \\
\text { Respond to Vocal } \\
\text { No PB }\end{array}$ \\
\hline 7 & $\begin{array}{l}\text { Attend } \\
\text { Respond to Model } \\
\text { No PB }\end{array}$ & $\begin{array}{l}\text { Attend } \\
\text { Respond to Model } \\
\text { No PB }\end{array}$ & $\begin{array}{l}\text { No attending } \\
\text { Respond to vocal } \\
\text { No PB }\end{array}$ \\
\hline 8 & $\begin{array}{l}\text { Attend } \\
\text { Error on Vocal } \\
\text { Respond on Model } \\
\text { No PB }\end{array}$ & $\begin{array}{l}\text { Attend } \\
\text { Respond with Vocal } \\
\text { No PB }\end{array}$ & $\begin{array}{l}\text { Attend } \\
\text { Error to Vocal } \\
\text { Error to Model } \\
\text { Respond to Physical } \\
\text { No PB }\end{array}$ \\
\hline 9 & $\begin{array}{l}\text { Attend } \\
\text { No Response to Vocal } \\
\text { Engage in PB } \\
\text { Respond to Model }\end{array}$ & $\begin{array}{l}\text { Attend } \\
\text { Respond to Vocal } \\
\text { No PB }\end{array}$ & $\begin{array}{l}\text { Attend } \\
\text { No Response to Model } \\
\text { Respond to Physical } \\
\text { No PB }\end{array}$ \\
\hline 10 & $\begin{array}{l}\text { Attend } \\
\text { Respond to Vocal } \\
\text { No PB }\end{array}$ & $\begin{array}{l}\text { Attend } \\
\text { Respond to Vocal } \\
\text { No PB }\end{array}$ & $\begin{array}{l}\text { Attend } \\
\text { Respond to Model } \\
\text { No PB } \\
\end{array}$ \\
\hline $\begin{array}{l}\text { Over- } \\
\text { view }\end{array}$ & $\begin{array}{l}3 \text { Vocal } \\
4 \text { Model } \\
3 \text { Physical }\end{array}$ & $\begin{array}{l}4 \text { Vocal } \\
3 \text { Model } \\
3 \text { Physical }\end{array}$ & $\begin{array}{l}3 \text { Vocal } \\
3 \text { Model } \\
4 \text { Physical }\end{array}$ \\
\hline
\end{tabular}


Appendix G.

Feedback Scripts

Modified from Giannakakos, Vladescu, Kisamore, Reeve (2016)

Least-to-Most Prompting

Begin with providing positive things done during session "During this session you did a good job,

Feedback is listed according to each step on the integrity data sheet. Read the corresponding sections relevant components if the parent made an error during that step, otherwise provide praise on that component.

\begin{tabular}{|c|c|}
\hline Step & Comment on Errors \\
\hline Secure attending & $\begin{array}{l}\text { a. When a trial begins, remember to get the child to look at the stimuli before presenting } \\
\text { the instruction. You can say "look" and point to the card(s). }\end{array}$ \\
\hline $\begin{array}{l}\text { Present session } \\
\text { materials }\end{array}$ & a. At the start of a trial present the materials for the trial before giving an instruction \\
\hline Present Instruction & $\begin{array}{l}\text { a. Always provide the instruction before providing a prompt } \\
\text { b. Use a clear, audible voice to provide the instruction }\end{array}$ \\
\hline $\begin{array}{l}\text { Deliver Correct } \\
\text { Prompt (order) }\end{array}$ & $\begin{array}{l}\text { a. The prompts used during this procedure from least intrusive to most intrusive are tell, } \\
\text { show, do. } \\
\text { b. On each trial, you should begin with the tell prompt. If the child does not engage in a } \\
\text { correct response, you should use a show (model) prompt. If the child is not successful, } \\
\text { you should use a do (physical prompt). } \\
\text { c. Provide additional examples if necessary } \\
\text { d. If the child engages in (does not respond, engages in an error or problem behavior), the } \\
\text { intrusiveness of the prompt should be increased during each trial. }\end{array}$ \\
\hline $\begin{array}{l}\text { Performs prompt } \\
\text { correctly (way) }\end{array}$ & $\begin{array}{l}\text { a. When providing a do prompt, provide hand-over-hand. (or as much is needed to prompt } \\
\text { the correct response) } \\
\text { b. When providing a show prompt, model for the child by pointing to the correct response } \\
\text { c. When providing a tell prompt, give the child the instruction only. } \\
\text { d. Prompts should be spaced out by } 5 \mathrm{~s}\end{array}$ \\
\hline $\begin{array}{l}\text { Provide praise and a } \\
\text { reinforcer when } \\
\text { appropriate }\end{array}$ & $\begin{array}{l}\text { a. Praise and a preferred item should be paired with correct responses } \\
\text { b. If the child engages in an error or no response, no feedback should be provided besides } \\
\text { a prompt }\end{array}$ \\
\hline $\begin{array}{l}\text { Remove stimuli after } \\
\text { trial }\end{array}$ & $\begin{array}{l}\text { a. After the trial ends (e.g., correct response, prompted response, etc.) all stimuli on the } \\
\text { table should be removed before the next trial begins } \\
\text { b. All materials should remain on the table during each trial }\end{array}$ \\
\hline Record data & $\begin{array}{l}\text { When recording data... } \\
\text { - Circle a }+ \text { if the child engages in a correct response with only the vocal instruction } \\
\text { within } 5 \mathrm{~s} \text {. } \\
\text { - Circle a "- }- \text { " if the child engages in an error, no response, or needs a prompt } \\
\text { (model/physical). } \\
\text { - Circle the prompt that occasioned the correct response } \\
\text { - Circle if the child engaged in problem behavior }(+,-)\end{array}$ \\
\hline $\begin{array}{l}\text { Ignore problem } \\
\text { behavior }\end{array}$ & $\begin{array}{l}\text { a. If the child engages in problem behavior that is not dangerous to his/her, keep a neutral } \\
\text { facial expression and do not attend to this behavior. Continue with the procedures for } \\
\text { the current trial. } \\
\text { b. Move to a more intrusive prompt following problem behavior }\end{array}$ \\
\hline $\begin{array}{l}\text { Present next trial } \\
\text { within } 5 \mathrm{~s}\end{array}$ & $\begin{array}{l}\text { a. After a trial ends, the next stimuli should be presented within } 5 \mathrm{~s} \text { or less (e.g., of } \\
\text { reinforcement removal). }\end{array}$ \\
\hline
\end{tabular}


Vary order of array

a. Change the order you place stimuli on the table during each trial. (For example, the same target should not always be in the center).

Ask if parent has any questions at the end

"Do you have any questions?" 
Begin with providing positive things done during session "During this session you did a good job,

Feedback is listed according to each step on the integrity data sheet. Read the corresponding sections relevant components if the parent made an error during that step, otherwise provide praise on that component.

\begin{tabular}{|c|c|}
\hline Step & Comment on Errors \\
\hline Secure attending & $\begin{array}{l}\text { a. When a trial begins, remember to get the child to look at the stimuli before presenting } \\
\text { the instruction. You can say "look" and point to the card(s). }\end{array}$ \\
\hline $\begin{array}{l}\text { Present session } \\
\text { materials }\end{array}$ & a. At the start of a trial present the materials for the trial before giving an instruction \\
\hline Present Instruction & $\begin{array}{l}\text { a. Always provide the instruction before providing a prompt } \\
\text { b. Use a clear, audible voice to provide the instruction }\end{array}$ \\
\hline $\begin{array}{l}\text { Deliver Correct } \\
\text { Prompt (order) }\end{array}$ & $\begin{array}{l}\text { a. The prompts used during this procedure from a short delay }(0 \mathrm{~s}) \text { to a longer delay }(2 \mathrm{~s}, 5 \\
\mathrm{s}) \\
\text { b. If the child gets a correct response during the delay, the next trial should begin with a } \\
\text { longer delay. } \\
\text { c. If the child does not get the correct response or during the delay, the next trial should } \\
\text { begin with a shorter delay } \\
\text { d. Provide additional examples if necessary } \\
\text { e. If the child engages in (does not respond, engages in an error or problem behavior), a } \\
\text { prompt should be provided. Do not increase the intrusiveness of the prompt (e.g., } \\
\text { physical) }\end{array}$ \\
\hline $\begin{array}{l}\text { Performs prompt } \\
\text { correctly }\end{array}$ & $\begin{array}{l}\text { a. You should only provide vocal instructions and show prompts } \\
\text { b. Prompts should be provided at the assigned time delay. } \\
0 \text { s prompts should be provided immediately } \\
2 \mathrm{~s} \text { prompts should be provided after a count of } 2 \\
5 \mathrm{~s} \text { prompts should be provided after waiting } 5 \mathrm{~s} \\
\text { c. Do not provide an additional prompt during the delay period } \\
\text { d. When providing a show prompt, model for the child by pointing to the correct response } \\
\text { e. When providing a tell, prompt give the child the instruction only. }\end{array}$ \\
\hline $\begin{array}{l}\text { Provide praise and a } \\
\text { reinforcer when } \\
\text { appropriate }\end{array}$ & $\begin{array}{l}\text { a. Praise and a preferred item should be paired with correct responses } \\
\text { b. If the child engages in an error or no response, no feedback should be provided besides } \\
\text { a prompt }\end{array}$ \\
\hline $\begin{array}{l}\text { Remove stimuli after } \\
\text { trial }\end{array}$ & $\begin{array}{l}\text { a. After the trial ends (e.g., correct response, prompted response, etc.) all stimuli on the } \\
\text { table should be removed before the next trial begins } \\
\text { b. All materials should remain on the table during the trial }\end{array}$ \\
\hline Record data & $\begin{array}{l}\text { When recording data... } \\
\text { - Circle a }+ \text { if the child engages in a correct response with only the vocal instruction } \\
\text { within } 5 \mathrm{~s} \text {. } \\
\text { - Circle a "- " if the child engages in an error, no response, or needs a model prompt } \\
\text { - Circle what prompt delay was used } \\
\text { - Circle if the child engaged in problem behavior }(+,-)\end{array}$ \\
\hline $\begin{array}{l}\text { Ignore problem } \\
\text { behavior }\end{array}$ & $\begin{array}{l}\text { a. If the child engages in problem behavior that is not dangerous to his/her, keep a neutral } \\
\text { facial expression and do not attend to this behavior. Continue with the procedures for } \\
\text { the current trial. }\end{array}$ \\
\hline $\begin{array}{l}\text { Present next trial } \\
\text { within } 5 \mathrm{~s}\end{array}$ & $\begin{array}{l}\text { a. After a trial ends, the next stimuli should be presented within } 5 \mathrm{~s} \text { or less (e.g., of } \\
\text { reinforcement removal). }\end{array}$ \\
\hline
\end{tabular}


a. Change the order you place stimuli on the table during each trial. (For example, the same target should not always be in the center).

Ask if parent has any questions at the end

"Do you have any questions?" 


\section{Most-to-Least Prompting}

Begin with providing positive things done during session "During this session you did a good job,

Feedback is listed according to each step on the integrity data sheet. Read the corresponding sections relevant components if the parent made an error during that step, otherwise provide praise on that component.

\begin{tabular}{|c|c|}
\hline Step & Comment on Errors \\
\hline Secure attending & $\begin{array}{l}\text { b. When a trial begins, remember to get the child to look at the stimuli before presenting } \\
\text { the instruction. You can say "look" and point to the card(s) }\end{array}$ \\
\hline $\begin{array}{l}\text { Present session } \\
\text { materials }\end{array}$ & b. At the start of a trial, present the materials for the trial before giving an instruction \\
\hline Present Instruction & $\begin{array}{l}\text { c. Always provide the instruction before providing a prompt } \\
\text { d. Use a clear, audible voice to provide the instruction }\end{array}$ \\
\hline $\begin{array}{l}\text { Deliver Correct } \\
\text { Prompt (order) }\end{array}$ & $\begin{array}{l}\text { a. The prompts used during this procedure from most intrusive to least intrusive are do, } \\
\text { show, tell. } \\
\text { b. If the child is successful with the prompt type you use, the next trial should begin with } \\
\text { a less intrusive type by one level. } \\
\text { c. If the child is unsuccessful with the prompt you begin a trial with, the instruction } \\
\text { should be repeated and a prompt one level higher will be provided until the do prompt } \\
\text { is reached or a correct prompted response occurs. } \\
\text { d. Provide additional examples if necessary } \\
\text { e. If the child engages in (does not respond, engages in an error, or engages in problem } \\
\text { behavior), the intrusiveness of the prompt should be increased }\end{array}$ \\
\hline $\begin{array}{l}\text { Performs prompt } \\
\text { correctly }\end{array}$ & $\begin{array}{l}\text { a. When providing a do prompt, provide hand-over-hand (or as much is needed to prompt } \\
\text { the correct response) } \\
\text { b. When providing a show prompt, model for the child by pointing to the correct response } \\
\text { c. When providing a tell prompt, give the child the instruction only. } \\
\text { d. Prompts should be spaced out by } 5 \mathrm{~s}\end{array}$ \\
\hline $\begin{array}{l}\text { Provide praise and a } \\
\text { reinforcer when } \\
\text { appropriate }\end{array}$ & $\begin{array}{l}\text { a. Praise and a preferred item should be paired with correct responses } \\
\text { b. If the child engages in an error or no response, no feedback should be provided besides } \\
\text { a prompt }\end{array}$ \\
\hline $\begin{array}{l}\text { Remove stimuli after } \\
\text { trial }\end{array}$ & $\begin{array}{l}\text { a. After the trial ends (e.g., correct response, prompted response, etc.), all materials on the } \\
\text { table should be removed before the next trial begins } \\
\text { b. The materials should remain on the table during each trial }\end{array}$ \\
\hline Record data & $\begin{array}{l}\text { When recording data... } \\
\text { - Circle a }+ \text { if the child engages in a correct response with only the vocal instruction } \\
\text { within } 5 \mathrm{~s} \\
\text { - Circle a "- }- \text { " if the child engages in an error, no response, or needs a prompt } \\
\text { (model/physical) } \\
\text { - Circle the prompt that occasioned a correct response } \\
\text { - Circle if the child engaged in problem behavior }(+,-)\end{array}$ \\
\hline $\begin{array}{l}\text { Ignore problem } \\
\text { behavior }\end{array}$ & $\begin{array}{l}\text { a. If the child engages in problem behavior that is not dangerous to him/her, keep a } \\
\text { neutral facial expression and do not attend to this behavior. Continue with the } \\
\text { procedures for the current trial. } \\
\text { b. Move to a more intrusive prompt following problem behavior }\end{array}$ \\
\hline $\begin{array}{l}\text { Present next trial } \\
\text { within } 5 \mathrm{~s}\end{array}$ & $\begin{array}{l}\text { a. After a trial ends, the next stimuli should be presented within } 5 \mathrm{~s} \text { or less (e.g., of } \\
\text { reinforcement removal). }\end{array}$ \\
\hline
\end{tabular}


b. Change the order you place stimuli on the table during each trial. (For example, the same target should not always be in the center).

Ask if parent has any questions at the end

"Do you have any questions?" 
Appendix H.

TREATMENT EVALUATION INVENTORY SHORT FORM- REVISED (TEI- SF)

(Kelley, Heffer, Gresham, \& Elliot, 1989)

Please complete the items listed below. The items should be completed by placing a check mark on the line under the question that best indicates how you feel about the treatment recommendations. Please read the items very carefully because a checkmark accidentally placed on one space rather than another may not represent the meaning you intend.

\section{I find this treatment to be an acceptable way of teaching a child this skill}

$\overline{\text { strongly disagree }} \overline{\text { disagree }} \quad \overline{\text { neutral }} \quad \overline{\text { agree }} \quad \overline{\text { strongly agree }}$

2. I believe that it would be acceptable to use this treatment without the child's consent

$\overline{\text { strongly disagree }} \overline{\text { disagree }} \quad \overline{\text { neutral }} \quad \overline{\text { agree }} \quad \overline{\text { strongly agree }}$

3. I like the procedures used in this treatment

$\overline{\text { strongly disagree }} \overline{\text { disagree }} \quad \overline{\text { neutral }} \quad \overline{\text { agree }} \quad \overline{\text { strongly agree }}$

4. I believe this treatment is likely to be effective

$\overline{\text { strongly disagree }} \overline{\text { disagree }} \quad \overline{\text { neutral }} \quad \overline{\text { agree }} \quad \overline{\text { strongly agree }}$

5. I believe the child will experience discomfort during this treatment

$\overline{\text { strongly disagree }} \overline{\text { disagree }} \quad \overline{\text { neutral }} \quad \overline{\text { agree }} \quad \overline{\text { strongly agree }}$

6. I believe it would be acceptable to use this treatment with individuals who cannot choose treatments for themselves

$\overline{\text { strongly disagree }} \overline{\text { disagree }} \quad \overline{\text { neutral }} \quad \overline{\text { agree }} \quad \overline{\text { strongly agree }}$ 
7. Overall, I have a positive reaction to this treatment

$\overline{\text { strongly disagree }} \overline{\text { disagree }} \quad \overline{\text { neutral }} \quad \overline{\text { agree }} \quad \overline{\text { strongly agree }}$

8. I would suggest this treatment to someone else

$\overline{\text { strongly disagree }} \overline{\text { disagree }} \quad \overline{\text { neutral }} \quad \overline{\text { agree }} \quad \overline{\text { strongly agree }}$

Comments: 
Appendix I.

Parent Initials:

Date: Time completed: \#1 \#2 \#3

Draw a line on the scale at what point you would consider a procedure to be 'unacceptable' and would not want to implement it.

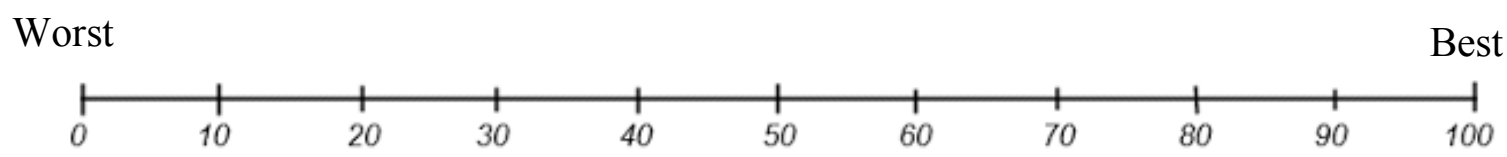

Please rate each of the prompt procedures on a scale of $0-100$ by writing the corresponding value on the line next to each question.

How would you rate Least-to-Most prompting on a scale of 0-100?

Why did you give it this rating?

How would you rate Progressive-Prompt-delay on a scale of 0-100?

Why did you give it this rating?

How would you rate Most-to-Least prompting on a scale of 0-100?

Why did you give it this rating? 